\title{
COMPRESSIVE PERFORMANCE OF COLD-FORMED THIN-WALLED STEEL CHANNNEL SECTIONS IN FIRE
}

\author{
Y.C. Wang1, M.Q. Feng and B. Salhab \\ ${ }^{1}$ School of Mechanical, Aerospace and Civil Engineering (MACE), University of Manchester, UK. \\ Email: yong.wang@umist.ac.uk
}

\begin{abstract}
This paper presents the main results of an extensive study of the compressive performance of cold-formed thin-walled steel sections under conditions of fire, recently conducted by the authors. Experimental, numerical and design calculation studies were performed. The experiments include:

- Fire tests on small panels, measuring 300 x $300 \mathrm{~mm}$, consisting of a solid or perforated cold-formed thin-walled steel channel section, one or two layers of $12.5 \mathrm{~mm}$ thick gypsum plasterboard on both sides and either with or without interior insulation, exposed to the standard BS 476 fire condition on one side;

- Compression tests on short (400 mm) channel sections at various uniform elevated temperatures up to $700^{\circ} \mathrm{C}$;

- Fire tests on six full-scale panels of $2.2 \times 2.0 \mathrm{~m}$, each consisting of three cold-formed thin-walled steel channel sections, one layer of $12.5 \mathrm{~mm}$ gypsum plasterboard on both sides and with interior insulation, exposed to the standard BS 476 fire condition on one side;

- Fire test on one full-scale panel with the same arrangement as above, but using channel sections with perforations along the length of the web of the steel section.

Numerical studies, using ABAQUS, were carried out to investigate the following aspects:

- Validation of heat transfer analysis against the small panel fire test results;

- Structural behaviour of the short test columns under uniform temperature;

- Effect of non-uniform temperature distributions in the steel cross-section of a column on its structural behaviour;

- Effect of gypsum plasterboard falling on column structural behaviour.

The different current design methods were assessed by comparing the design calculation results against finite element simulation and experiment results.

It has been concluded that the behaviour of this type of construction is complex, affected by a number of factors of some of which our current understanding is poor, for example, how to predict gypsum plasterboard falling at high temperatures. ABAQUS is a useful tool for studying detailed thermal and structural behaviour of cold-formed thin-walled steel structures in fire. This paper shows that provided steel temperatures are available, ENV 1993-1-2 provides a reasonable and conservative prediction of ultimate strength and failure time of the samples tested in this study.
\end{abstract}

Keywords: Thin-walled structures, fire tests, fire resistance, elevated temperatures, thermal behaviour, heat transfer, perforation, gypsum plasterboard

\section{INTRODUCTION}

Recent studies of steel structural performance in fire have been intensive and progresses in this area rapid, but most of these studies have focused on hot-rolled steel products which represent a majority of the market share of steel framed building structures. Nevertheless, cold-formed thin-walled steel structures are widely used as primary load bearing members, for example in steel framed housing and apartment buildings. It is important that their performance in fire is adequately dealt with.

Because cold-formed thin-walled steel products are often used in proprietary systems, determination of whether a system comprising cold-formed thin-walled steel products has adequate 
fire resistance is based on the manufacturer of the system showing a certificate to state that a representative of such a system has passed the relevant standard fire resistance test. Leaving aside the well-publicised criticisms of using the standard fire resistance test as the only means of assessing structural performance in fire, the following issues are specifically related to cold-formed thin-walled steel structures that cannot be properly resolved by simply performing the standard fire resistance test:

(1) A system using cold-formed thin-walled steel structures can have many components. It cannot be possible to fire test every combination of the many different components in the system.

(2) The dimensions (e.g. the height) of a cold-formed thin-walled steel structural system can be different from those of the standard fire test sample. It may not be safe to extrapolate the standard fire test results to larger dimensions.

(3) The standard fire resistance test is expensive and time-consuming to perform, relying on it would slow down developments of better products in a competitive market.

The alternative is to develop better fundamental understanding of the fire performance of cold-formed thin-walled steel structures, which when combined with appropriate selection of a small number of confirmatory fire tests, would enable predictive and rational design methods to be developed for more economical and reliable use of cold-formed thin-walled steel structures in fire. Since only a small number of studies of the fire performance of cold-formed thin-walled steel structures have been performed, our understanding of this topic is still poor and the objective of this paper is to provide some results of the authors recent research to fill the gap in knowledge.

The three general aspects of dealing with structural performance in fire are: quantifying behaviour of the fire (fire dynamics), calculation of temperatures in the structure (heat transfer) and assessing structural behaviour at elevated temperatures (structural engineering). Although much of the general knowledge of these three aspects, gained from studies of hot-rolled steel structural performance in fire, can be adapted to cold-formed thin-walled steel structures, significant differences exist between structural systems using hot-rolled and cold-formed thin-walled steel products.

(1) Figure 1 shows a generic panel system using cold-formed thin-walled steel sections to which this paper is relevant. Since such construction usually forms part of the fire resistant construction of a building, fire exposure is from one side. Therefore, non-uniform temperature distributions will develop in the steel structure. The non-uniform temperature distribution is not only in the thickness direction of the panel, but also along the flanges of the steel sections as they are thin and heat dissipation along their flanges is relatively high compared to that in hot-rolled steel sections that are usually much thicker. Furthermore, fire exposure to hot-rolled steel structural sections is from all sides. Hence, if a hot-rolled steel section is protected, it is reasonable to assume that the steel temperature is uniform. If it is not protected, the different components of the steel section (e.g. flanges and web) may be assumed to have uniform temperature and it is easy to calculate these temperatures by using the individual section factors of the components.

(2) Cold-formed thin-walled steel structures are prone to various types of buckling and have to rely on other components of the system (e.g. plasterboards) to provide stability. On the contrary, in systems using hot-rolled steel sections, the strength and stiffness of these 
(3) components (if they exist) are insignificant compared to those of the hot-rolled section. To simplify structural analysis, they can be neglected.

(4) The structural behaviour of cold-formed thin-walled steel sections involves interaction of different buckling modes (local, distortional and global). This is far more complex than the relatively simple global buckling mode that governs the behaviour of thicker hot-rolled steel sections. Even in global buckling mode, the different types of restraint to cold-formed thin-walled steel sections make the structure prone to flexural buckling, torsional buckling or combined flexural-torsional buckling instead of the relatively simple flexural buckling problem in hot-rolled steel sections.

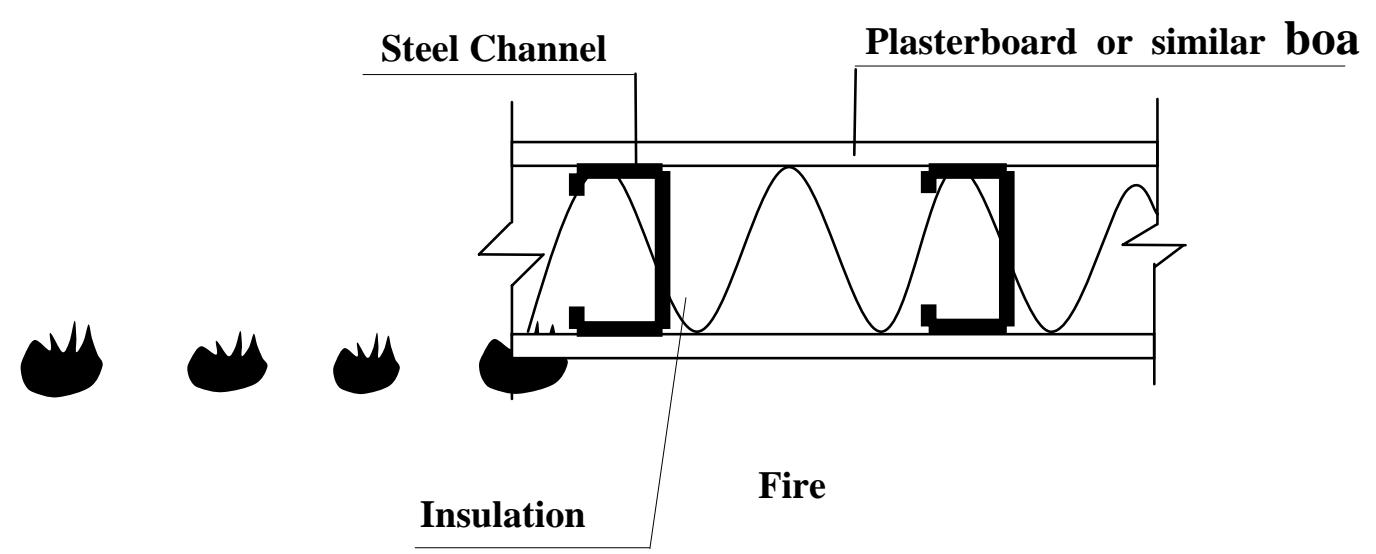

Figure 1. Cold-formed thin-walled steel in panel exposed to fire attack on one side

These fundamental differences between hot-rolled and cold-formed thin-walled steel sections make it necessary to study the fire performance of cold-formed thin-walled steel structures in a comprehensive manner so that rational performance based design guidance can be developed. Other major relevant research studies of cold-formed thin-walled steel structural performance in fire include those conducted in the National Research Council of Canada (Sultan [1], Alfawakhiri et al [2], Kodur \& Sultan [3], Sultan and Lougheed [4], Benichou \& Sultan [5]) and by Sakumoto et al [6] of Japan. Of the NRCC studies, Sultan [1] described a one-dimensional heat transfer program to predict temperatures in non-insulated unloaded steel-stud gypsum board wall assemblies exposed to fire, but the steel stud was not modelled on the basis of its small effect on heat transfer in the system. Alfawahkiri et al [2] provided a comprehensive review of relevant investigations until the late 1990s. The other NRCC papers and the Japanese research report provide the results of a large number of standard fire resistance tests on walls and floors using both wood sticks and thin-walled steel channel sections. In both sets of studies, the wall tests included both loaded and unloaded panels. From the NRCC loaded fire tests on steel stud walls, they concluded that the main factors that affect the fire resistance of steel stud walls were the type of interior insulation, stud spacing, number and type of boards and whether or resilient channel is present. They observed that the loaded walls without interior insulation had higher fire resistance than the ones with interior insulation. An explanation would be that the walls with interior insulation had higher temperature gradients through the thickness of the walls, thereby inducing higher thermal bowing deflections leading to increased P- $\delta$ effect. The NRCC observation on the non-loaded steel stud walls suggests that the interior insulation had exactly the opposite effect from that on the loaded walls. For the unloaded walls, the failure criterion was according to the temperature attained on the unexposed side of the wall. Without any interior insulation, the temperature gradient in the thickness direction of the wall was lower than with interior insulation, so that the temperature on the unexposed surface of the wall was higher, hence the fire resistance of the wall was lower according to the temperature criterion. The main additional conclusion from the 
study of Sakumoto et al [6] is that gypsum plasterboard falling could have significant effect on fire performance of the walls.

The above studies are mainly experimental ones. Whilst they would contribute to an invaluable database of experimental results (if and whenever their detailed results are made publicly available), their conclusions are general and any specific conclusion would only be applicable to the systems that they have tested. Complete understanding of the fire performance of this type of construction can only be gained through detailed experimental, numerical and analytical studies. This is the objective of the authors' research.

As previously mentioned, understanding the structural behaviour of a system in fire involves studies of fire dynamics, heat transfer and structural assessment. Fire behaviour is common to both hot-rolled and cold-formed thin-walled steel structures. Although our understanding of fire behaviour is far from complete, as far as structural performance is concerned, well accepted design guidance is available on this aspect [7]. This paper will concentrate on the thermal behaviour to obtain temperatures in the structure and structural assessment at elevated temperatures. This paper summarises the main findings of the authors' research and some more detailed information may be obtained from a number of other publications by the authors [8-14].

\section{THERMAL BEHAVIOUR}

Fire tests were performed on unloaded and loaded specimens. The unloaded tests were performed on small samples shown in Figure 2, which were $300 \times 300 \mathrm{~mm}$ in plan dimensions and consisted of one $300 \mathrm{~mm}$ long steel channel section and one or two layers of $12.5 \mathrm{~mm}$ thick Fireline gypsum plasterboard (manufactured by British Gypsum Limited) on each side. The steel section was either lipped channel (dimensions $100 \times 54 \times 15 \times 1.2 \mathrm{~mm}$ or $100 \times 56 \times 15 \times 2 \mathrm{~mm}$ ) or unlipped channel (dimensions 104 x 63 x $1.5 \mathrm{~mm}$ ) from Metsec. Both solid sections and sections with perforated web were tested. Perforated sections are commonly used in cold regions to reduce the effect of cold bridging in

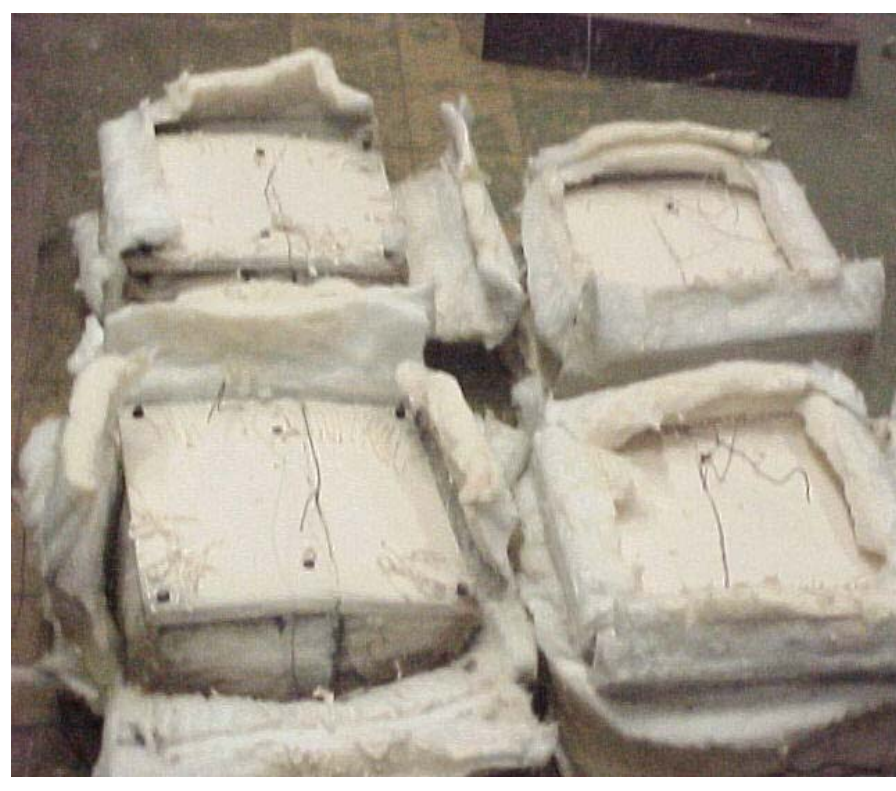

Figure 2. Small scale samples after fire test external walls. Some specimens using a solid steel section had interior insulation of the type Isowool 1000 mineral wool manufactured by British Gypsum Limited. Table 1 gives details of the test samples without perforation. For the test samples with perforation, Figure 3 shows the pattern and dimensions of perforation; the steel section was either of the above two lipped channel types; either one or two layers of gypsum plasterboard was used on each side and all samples had interior insulation Isowool 1000. Figure 4 shows the furnace used for these tests, which had four apertures of $300 \times 300 \mathrm{~mm}$ and allowed four small specimens to be tested at the same time. 


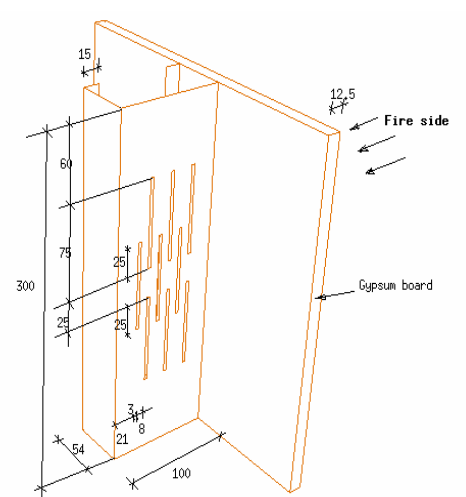

Figure 3. Pattern and dimensions of perforation

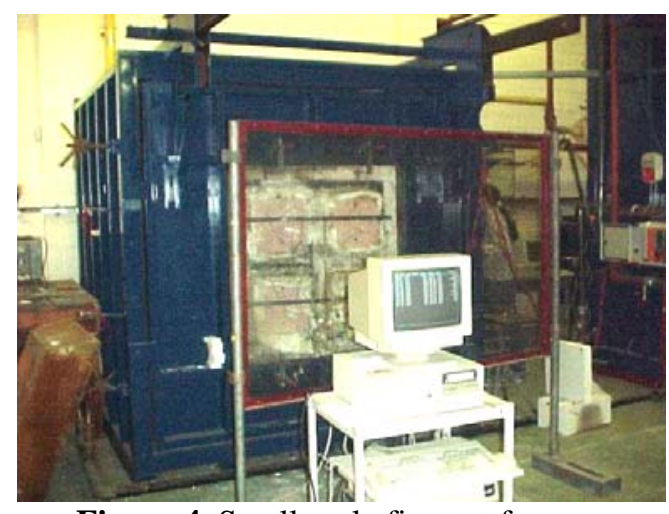

Figure 4. Small scale fire test furnace

Table 1. Small scale unloaded fire test specimens - no perforation

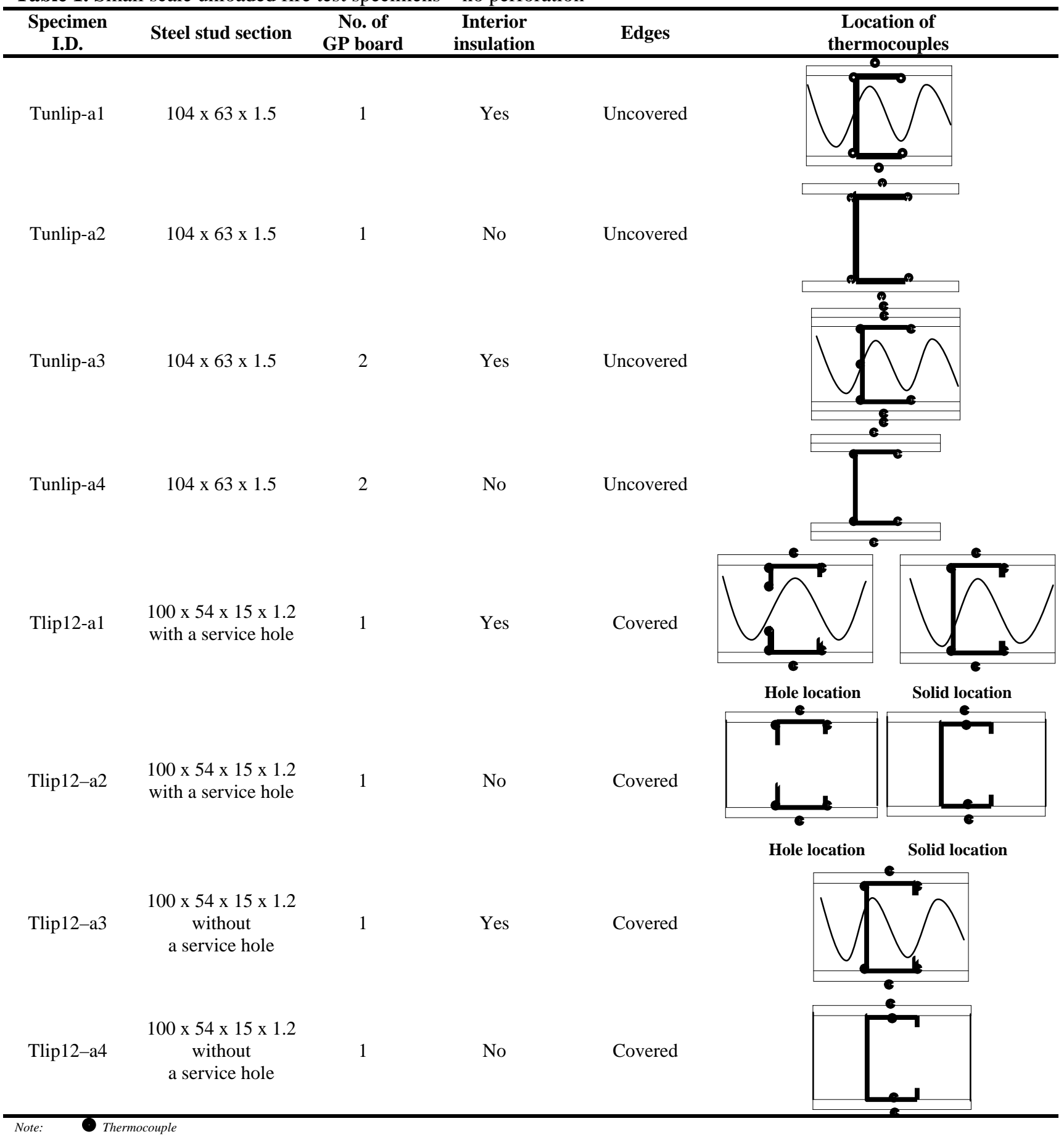


The seven loaded tests were performed on large panels of $2 \times 2.2 \times 0.125 \mathrm{~m}$ in dimensions, each consisting of three sections of either of the above two lipped channel types, spaced at $750 \mathrm{~mm}$ centres, with one layer of $12.5 \mathrm{~mm}$ thick Fireline gypsum plasterboard on each side and all having interior insulation Isowool 1000. Figure 5 shows dimensions of the loaded large scale panels and also a sketch of the fire test setup. Six tests had solid sections and one test had perforations along the web of the steel sections. The six tests using solid sections comprised three load ratios $(0.2,0.4$ and 0.7 ) for each of the two types of lipped steel channel sections. The load ratio was calculated as the applied load in the fire test to the panel load carrying capacity at ambient temperature, obtained from separate tests. The one test with perforated steel sections used lipped channel sections of dimensions $100 \times 54 \times 15 \times 1.2 \mathrm{~mm}$ and the same applied load as the panel with solid steel sections of the same dimensions at a load ratio of 0.4. Tables 2 summarises the main variables for the large (loaded) scale fire tests.

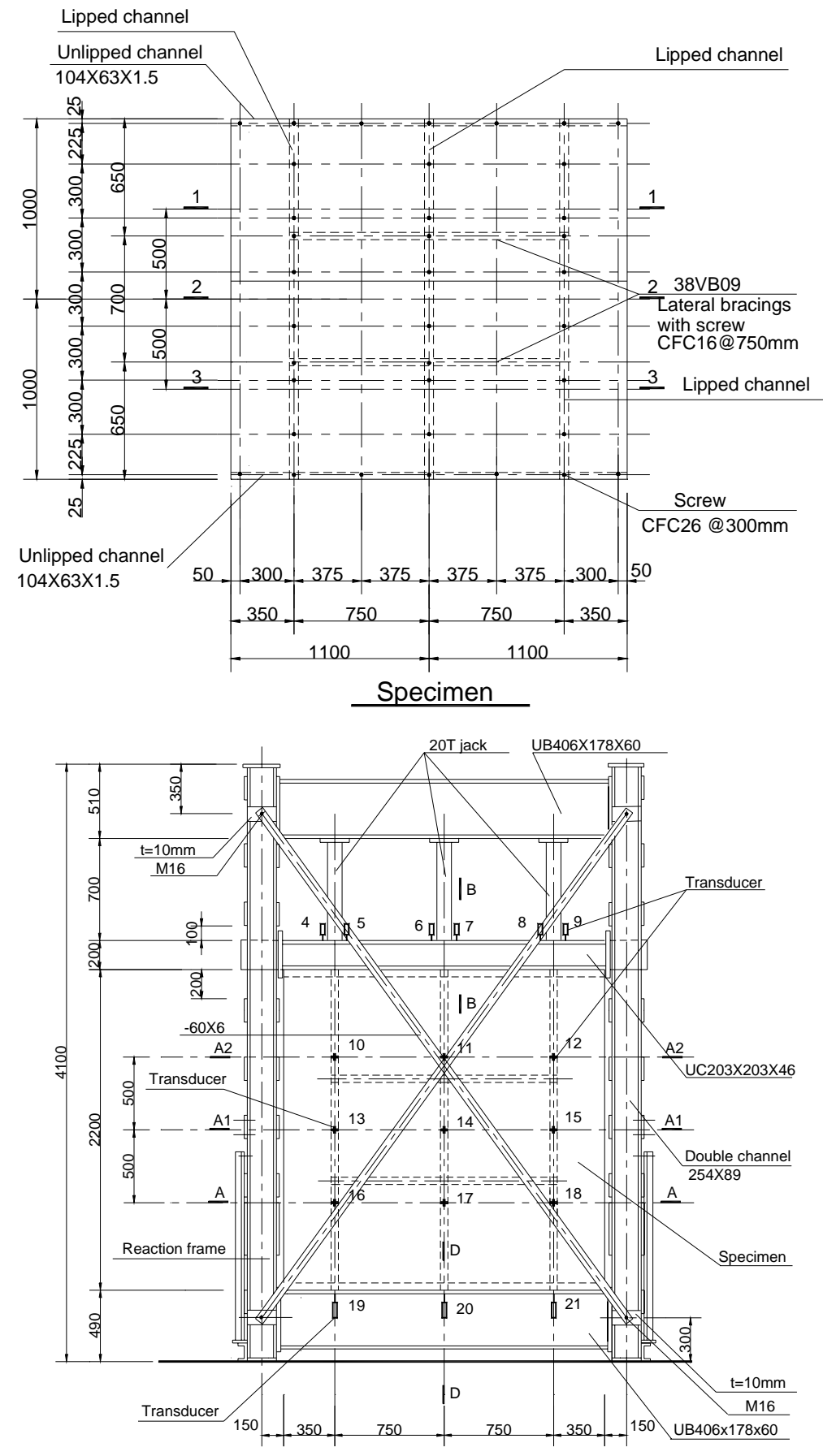

Figure 5. Large scale test: specimen dimensions and test set up 
In all tests, the fire exposure was from one side of the specimen and was according to the BS 476 [15] temperature - time relationship.

\subsection{Main observations and experimental results}

Figure 2 shows typical unloaded small scale test specimens after the fire test. A single crack was observed in the exposed gypsum plasterboard, but there was no detachment of the gypsum plasterboard. When interior insulation was used, it remained in place and did not shrink or get burnt. Figure 6 shows the measured temperatures in the various locations of a test specimen. It can be seen that the temperature distribution was highly non-uniform through the thickness of the test sample. There were also temperature gradients along both flanges of the steel section.

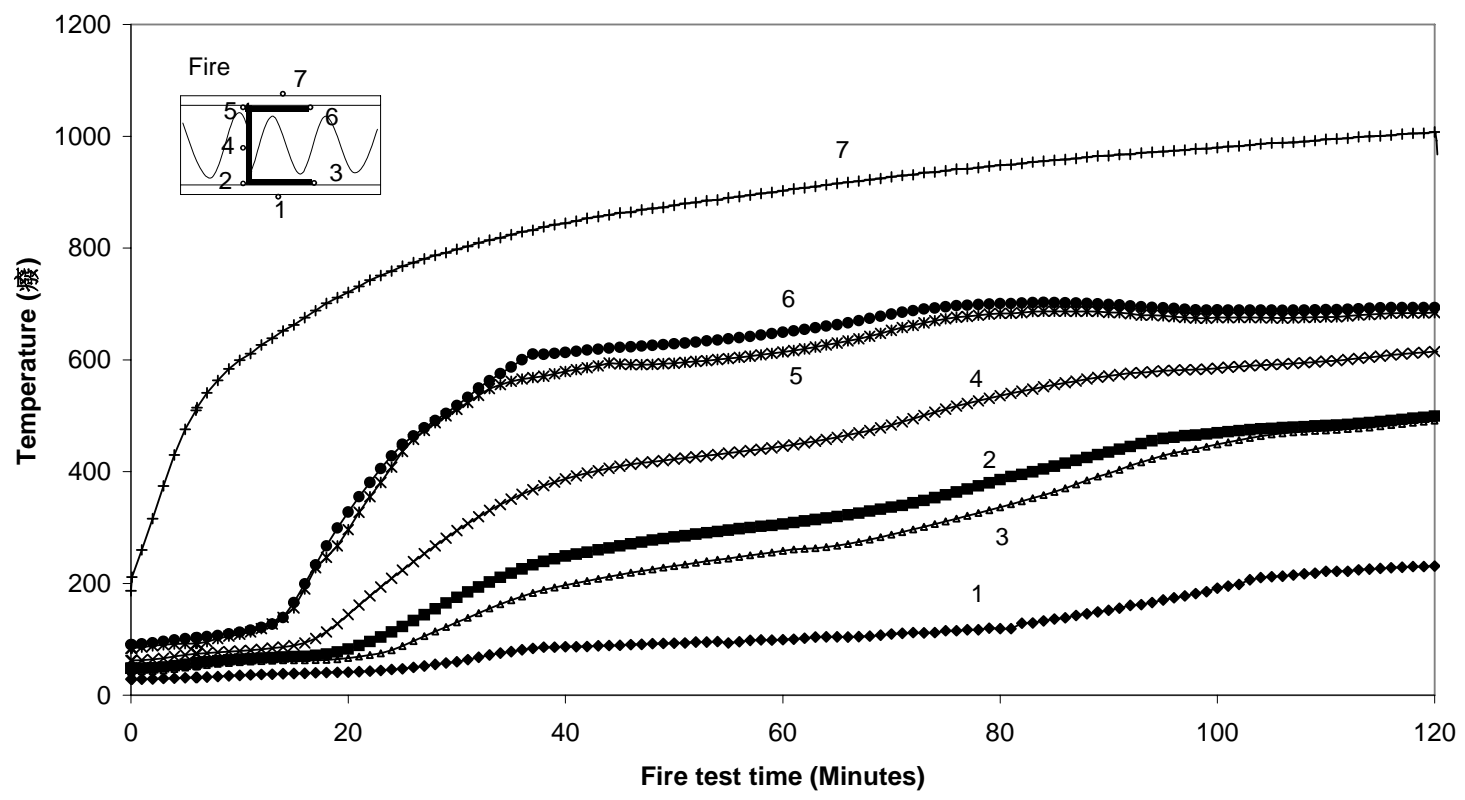

Figure 6. Time-temperature curves of unlipped channel 104 x 63 x 1.5 - single layer of gypsum board faces with mineral wool core

For the loaded large scale fire tests, behaviour of the gypsum plasterboard on the fire exposed side and the lightweight interior insulation were different. Figure 7 shows a large scale specimen after the fire test. In this case, some part of the interior insulation appeared to have shrunk whereby forming holes. This resulted in the steel section to attain near uniform temperature distribution as indicated in Figure 8 (compare temperatures recorded by thermocouples 2 and 3 with those by thermocouples 4 and 5). The test panel failed shortly afterwards. Shrinking of the interior insulation was possibly caused by direct contact with the fire flame which got into the interior insulation through the joint of the two exposed gypsum plasterboards that was not adequately sealed during the fire test. Clearly, the type of interior insulation as well as detailing of the gypsum plasterboards adopted in this study would not be adequate to provide sufficient fire protection. 

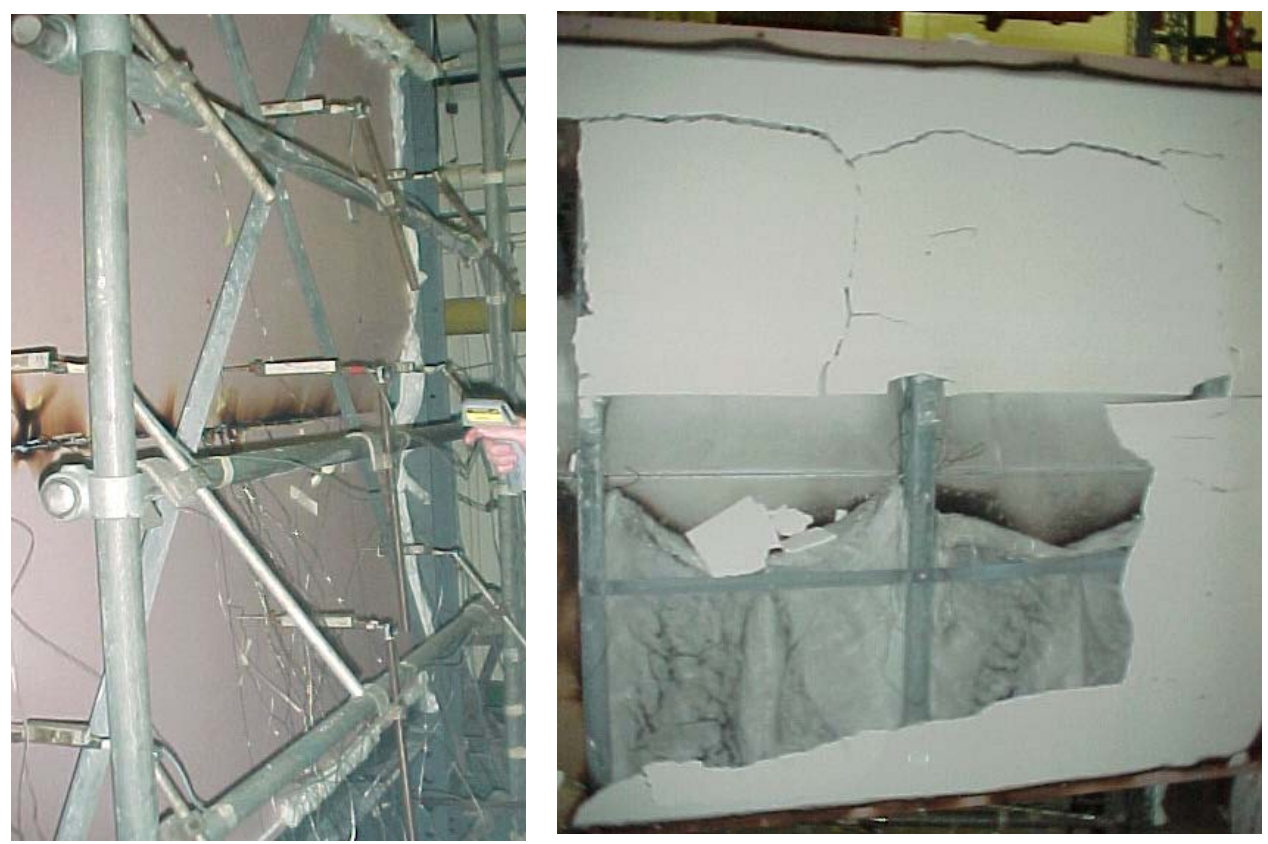

(a) Behaviour of gypsum plasterboard (before removal of plasterboard)
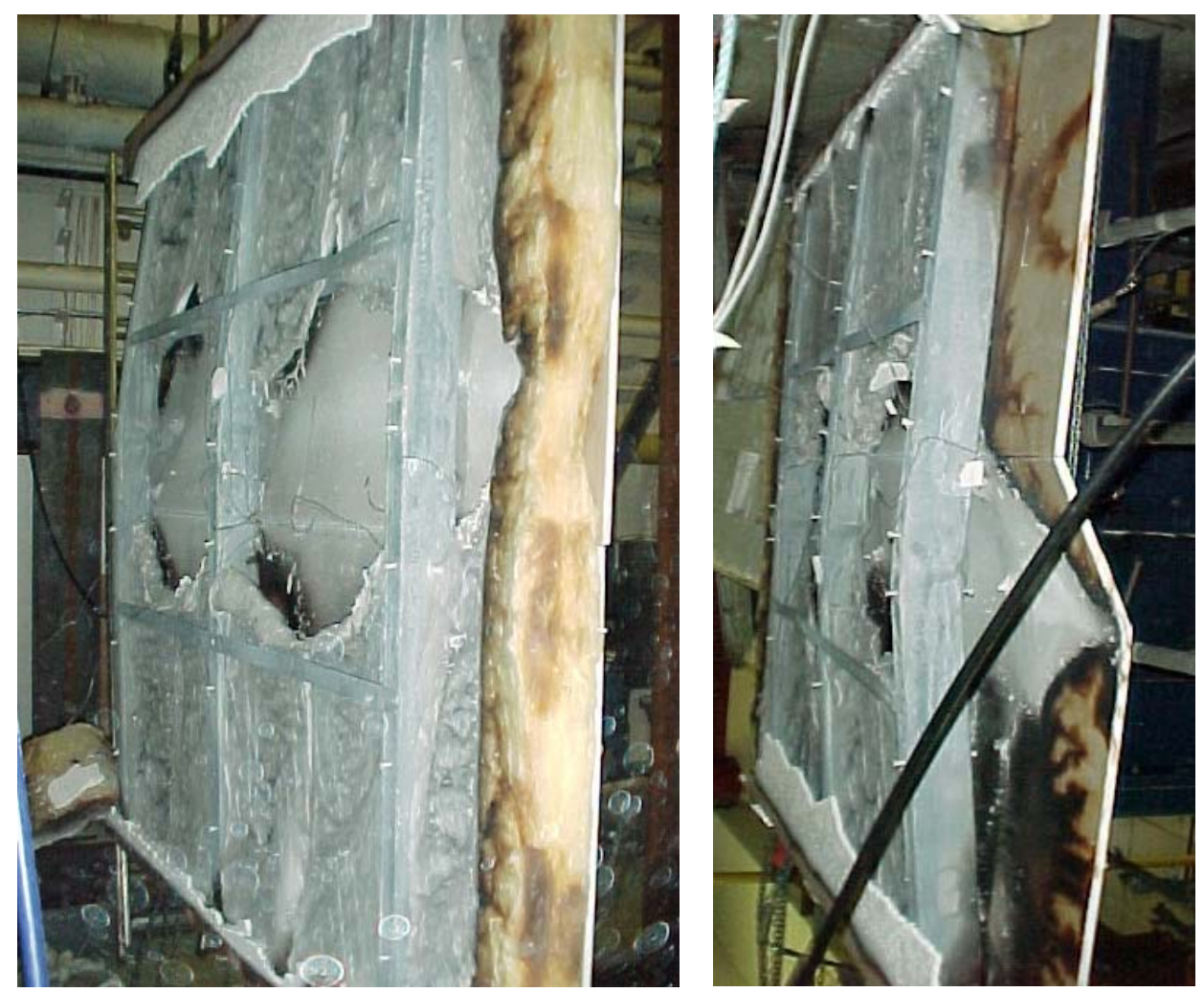

(b) Behaviour of steel studs (gypsum plasterboard removed for clarity)

Figure 7. Failure mode of panel using $100 \times 56$ x $15 \times 2$ sections under 0.2 load ratio 


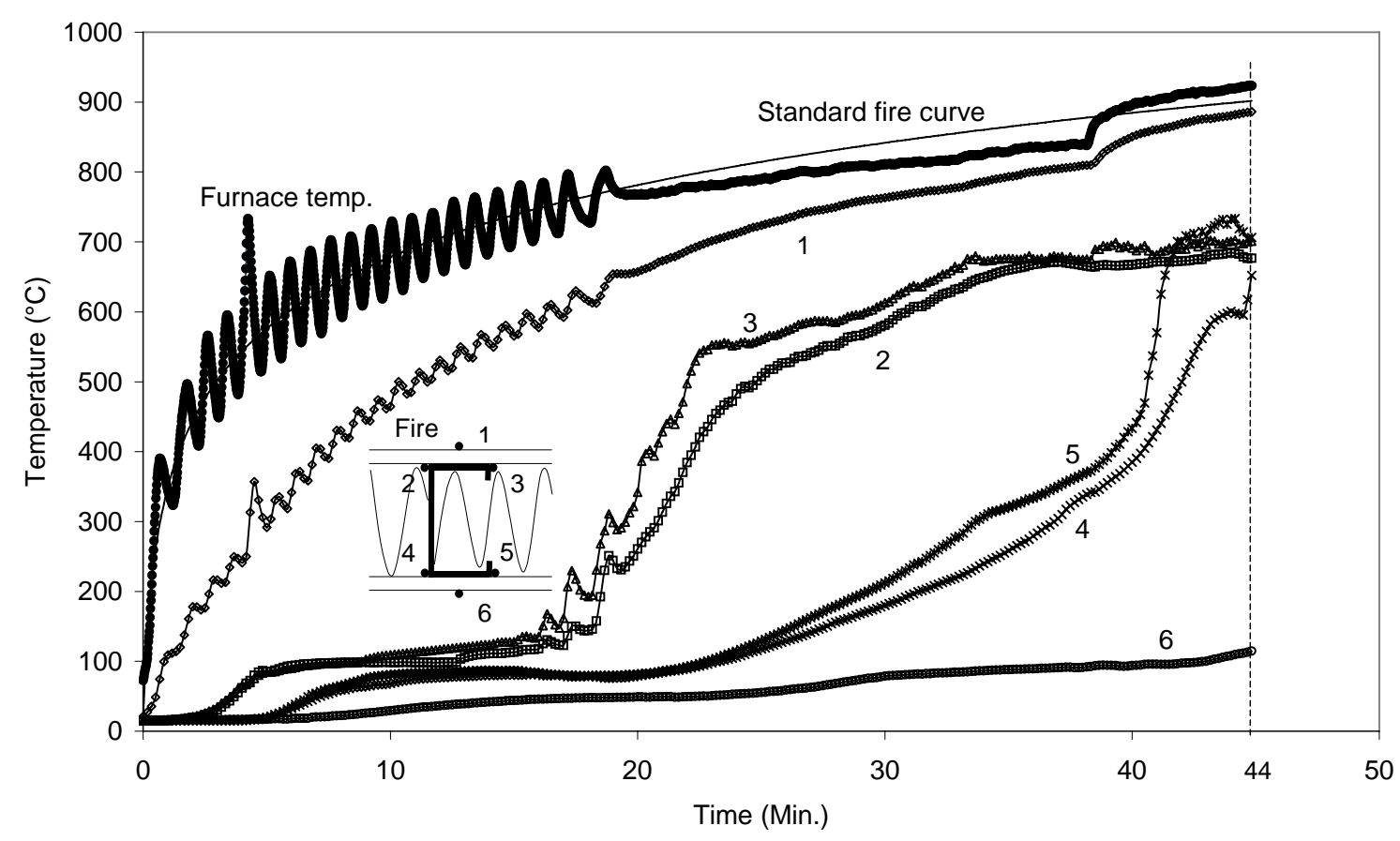

Figure 8. Time-temperature curves of large panel using 100 x 56 x 15 x 2 sections under 0.2 load ratio

In general, the performance of the gypsum plasterboard in a panel system, in particular whether and when it would fall during the fire exposure, will be an important factor. At this stage, it is not possible to draw any definitive conclusion from experimental observations of the authors study and of a number of other investigations. For loaded panels, Sakumoto et al [6] reported gypsum plasterboard falling in their tests. Figure 7 also shows that the gypsum plasterboard fell in the authors' own tests. However, Figure 8 shows that in the authors test, gypsum plasterboard falling was the effect, not the cause, of structural failure of the panel. This may be seen by comparing the recorded temperatures measured by thermocouple 1 on the exposed surface of the gypsum plasterboard and thermocouples 2 and 3 at the junction between the gypsum plasterboard and the steel section on the exposed side. The temperatures in the steel section (thermocouples 2 and 3 ) were always lower than that on the exposed surface of the gypsum plasterboard (thermocouple 1), indicating that the gypsum plasterboard had not fallen and was still offering fire protection to the steel sections. However, because it was not possible to view the exposed gypsum plasterboard during the fire test, it was not possible to definitely confirm this deduction. The fact that part of the gypsum plasterboard was missing after the fire test could have been a result of the large strains at structural failure of the steel sections, causing the already fragile gypsum plasterboard to fall, but such fall would not adversely affect the structural performance of the steel structure. The authors did not perform any large scale unloaded panel fire tests. The evidence of the fire tests of Sultan and Lougheed [4] appears to indicate that there was no gypsum plasterboard falling in their unloaded panel tests. However, the unloaded panel test results quoted in Sultan [1] indicate that gypsum plasterboard falling occurred when the exposed gypsum plasterboard temperature was about $600^{\circ} \mathrm{C}$. At present, observation of gypsum plasterboard performance in fire has been a by-product of studies of the steel section in panel system, rather than a subject in its own right. Considering the importance of this subject on the fire performance of the steel section in a panel system, studying the thermal and mechanical performance of stand-alone gypsum plasterboards will enable a better understanding and prediction of the panel system fire performance.

Figure 9 shows the recorded temperature - time relationships of one unloaded small scale test using perforated steel sections. One main point is that even the very narrow perforations were able to 
break the heat transfer paths and induce large temperature differences across the perforation (compare temperatures measured by thermocouples 4 and 5). However, because heat transfer in the perforated section was 3-dimensional in nature, the results in Figure 10 indicate that the difference between temperatures in the solid and perforated steel sections is small.

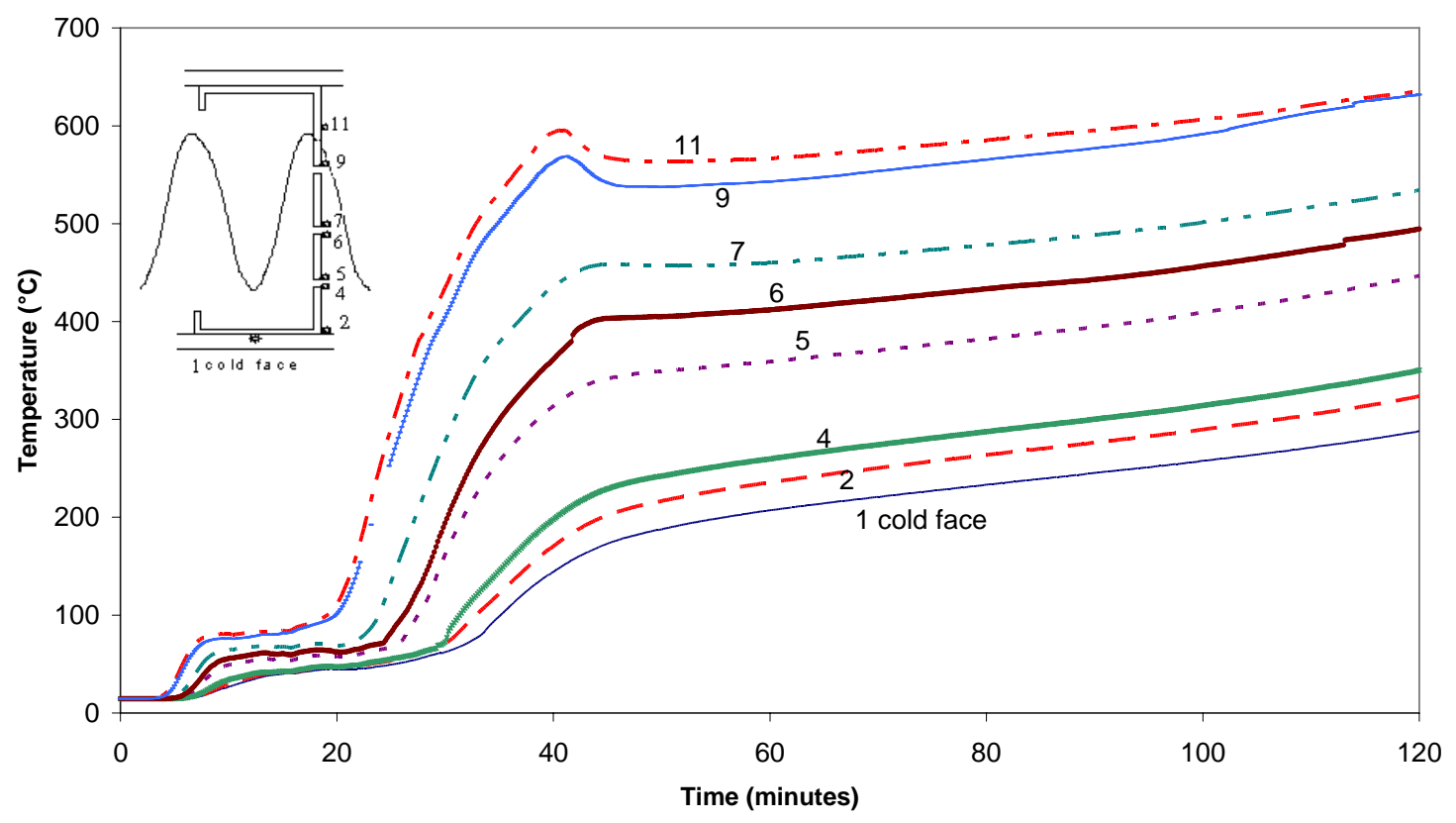

Figure 9. Time-temperature curves in $1.2 \mathrm{~mm}$ thick perforated section with one-layer gypsum plasterboard

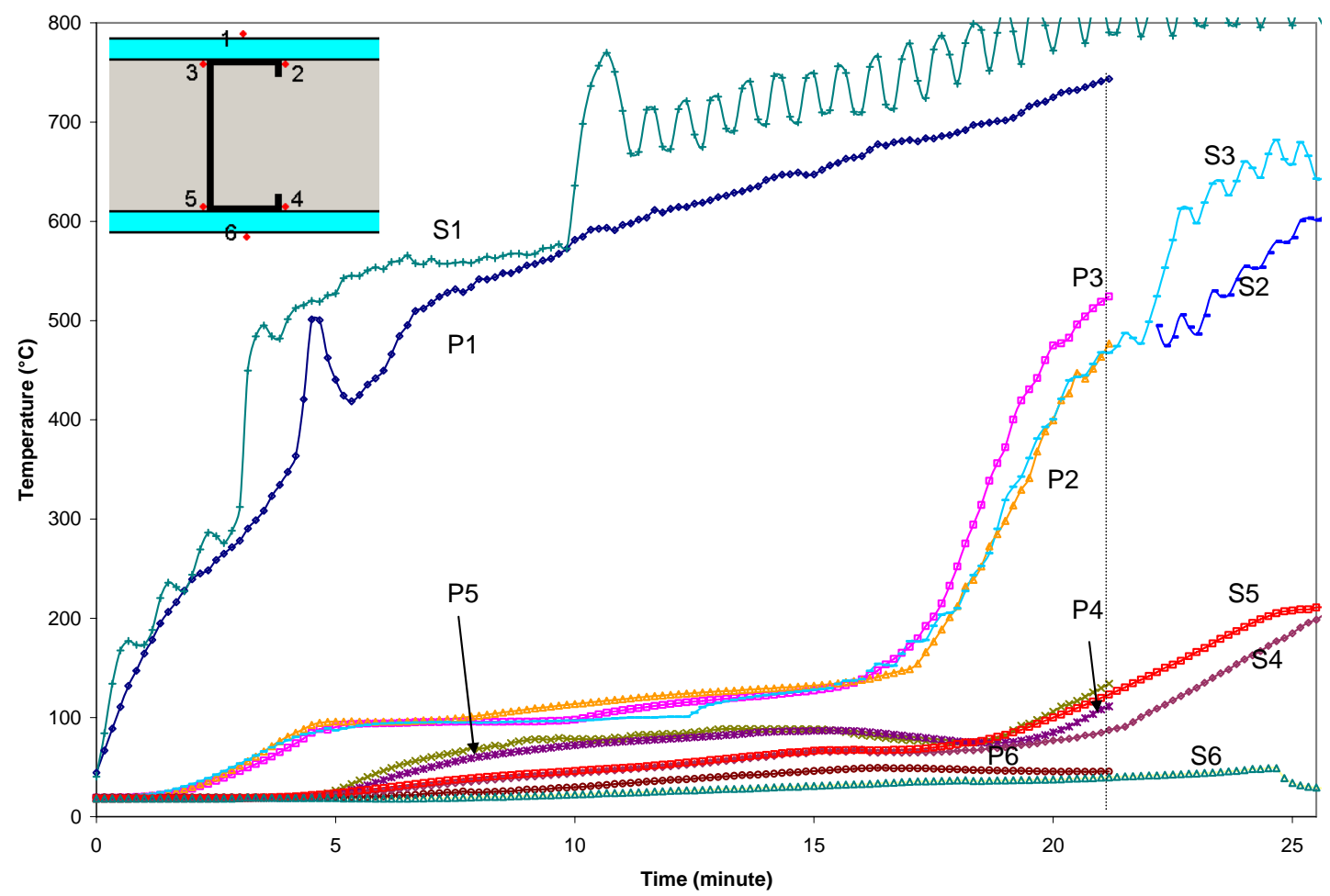

Figure 10. Comparison between temperature-time curves in perforated and solid sections, large panels, lipped channels of dimensions 100 x 54 x 15 x 1.2 mm (P for perforated section, $\mathrm{S}$ for solid section) 


\section{2}

\section{Numerical simulations}

The small-scale panel fire tests have been simulated using ABAQUS [16]. In the simulations, the gypsum plasterboard and the interior insulation were assumed to be intact during the entire fire exposure according to observation. Figure 11 shows the 2-dimensional finite element mesh used to simulate heat transfer in the small test panels using solid sections. Figure 12 shows typical comparison between the measured and simulated temperatures at various locations of one test. In the simulations, the thermal properties of steel were the same as in Eurocode 3 Part 1.2 [17]. The thermal properties of the gypsum plasterboard were based on Wang [18]. The thermal conductivity of Isowool 1000 was constant at $0.04 \mathrm{~W} /(\mathrm{mK})$, as given by the manufacturer. Figure 12 shows that correlation between the simulation and test results is reasonable. However, the simulated steel temperatures on the exposed side (thermocouples 4 and 5) are higher than the test results in the later stage of the fire test, while the simulated steel temperatures on the unexposed side (thermocouples 2 and 3) are lower than the test results. This may be attributed to the inaccurate values of thermal conductivity of Isowool 1000. At present, the only information is that from the manufacturer, however, this value is for ambient temperature only. According to Feng et al [10], the thermal conductivity of mineral wool would be higher at higher temperatures. If the actual values of thermal conductivity of mineral wool had been incorporated in numerical simulations, the temperature gradients would be reduced, improving correlation between the predicted and test results.

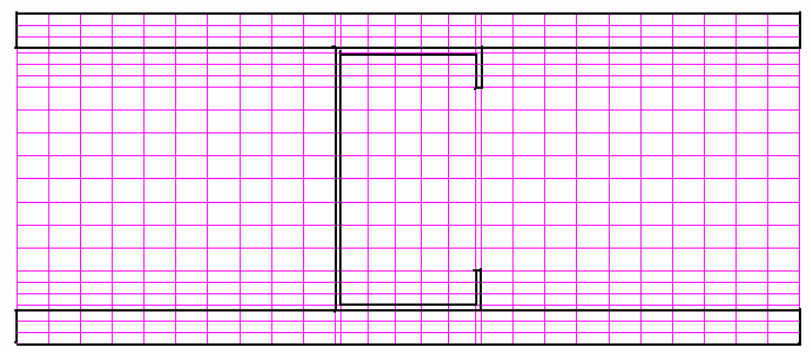

Figure 11. 2-Dimensional heat transfer finite element mesh

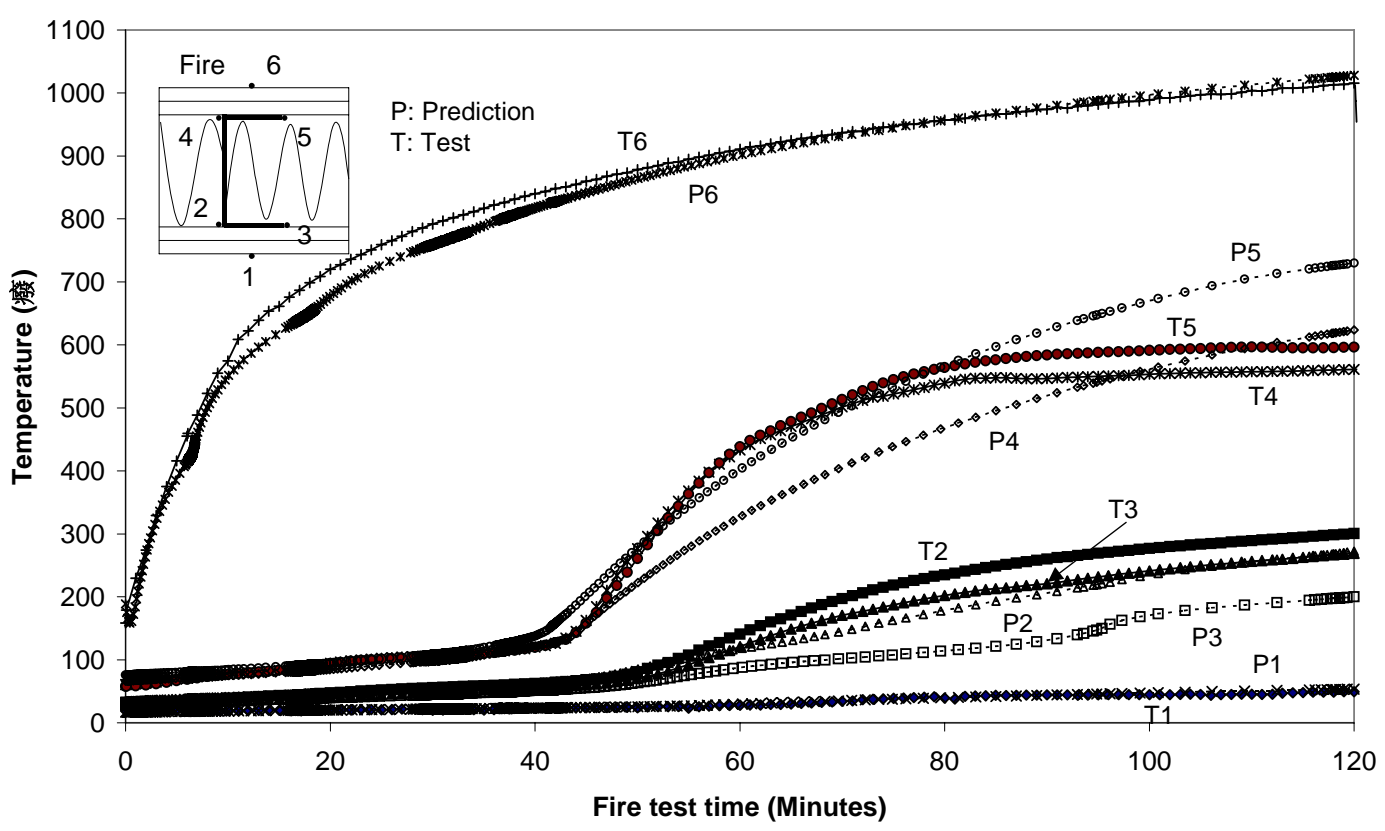

Figure 12. Comparison between test results and numerical analysis for unlipped channel 104 x 63 x 1.5 - double layers of gypsum board and mineral wool insulation 


\section{STRUCTURAL BEHAVIOUR}

Under realistic conditions of application as illustrated in Figure 1, the steel section will develop non-uniform temperature distribution in fire. During the author's research, tests and numerical studies were conducted on uniformly heated steel sections, so as to gain fundamental understanding of their performance at elevated temperatures, and on steel sections with non-uniform temperature distributions so that the realistic performance of this type of construction can be assessed.

\subsection{Uniform temperature study on short columns}

The uniform temperature study was conducted on short steel channel sections to investigate local and distortional bucking behaviour at elevated temperatures. A total of 52 tests were conducted on $400 \mathrm{~mm}$ long steel channel sections of three different types: unlipped channel section $104 \mathrm{x} 63 \mathrm{x}$ $1.5 \mathrm{~mm}$, lipped channel section 100 x 54 x 15 x $1.2 \mathrm{~mm}$ and lipped channel section $100 \times 56$ x $15 \times$ $2 \mathrm{~mm}$, some of the two lipped sections also having a service hole. These tests were conducted in an electrically heated kiln shown in Figure 13, at ambient temperature, $250^{\circ} \mathrm{C}, 400^{\circ} \mathrm{C}, 550^{\circ} \mathrm{C}$ and $700^{\circ} \mathrm{C}$, to provide information on their local and distortional buckling behaviour. In each test, the unloaded specimen was heated in an electrically heated kiln to the target temperature. Compression load was incrementally applied to the specimen until failure while maintaining the target temperature.

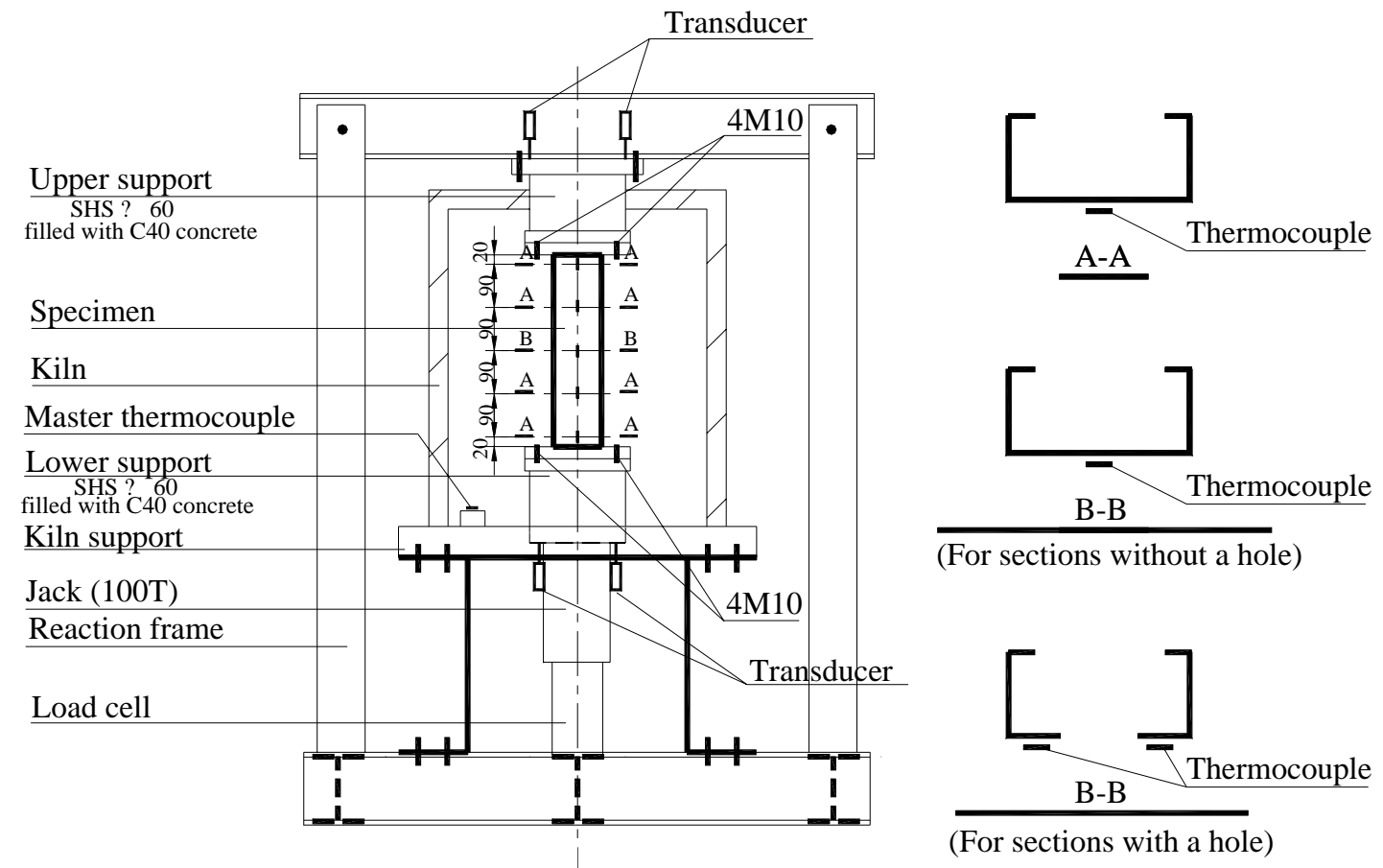

Figure 13. High temperature compression test rig

Table 2 gives the observed failure load and failure mode for each test. The experimental results clearly suggest that local buckling was associated with the unlipped and the thinner $(1.2 \mathrm{~mm})$ lipped sections and distortional buckling occurred more often in the thicker (2 mm) lipped sections. Whether local or distortional buckling would occur or not was also affected by the initial imperfection of the test specimen and the contact between the test specimen and the loading system. Thus, two nominally identical test specimens could fail in different modes. Nevertheless, as far as their failure loads are concerned, there was usually very little difference. These general conclusions 
are not affected by the level of elevated temperature. For example, Figure 14 shows the recorded load-axial deformation curves for the $2 \mathrm{~mm}$ thick lipped channel sections. Despite the difference in failure modes of some of the two nominally identical specimens, the recorded column deformation - temperature behaviour was very similar. Furthermore, Figure 15 shows that at each particular temperature, the short column strength for the different types of specimens, expressed as the ratio of the column strength at elevated temperature to that at ambient temperatures, varies within a relatively small range, suggesting that the limiting temperature approach such as that adopted in the SCI design guide for thin-walled steel structures [19], would be suitable.

Table 2. Failure modes and loads for short solid sections

\begin{tabular}{|c|c|c|c|c|}
\hline Section type & $\begin{array}{c}\text { Temp. } \\
\left({ }^{0} \mathrm{C}\right)\end{array}$ & $\begin{array}{c}\text { Name of } \\
\text { Specimens }\end{array}$ & Test Strength $\quad(k N)$ & Observed Failure mode \\
\hline $\begin{array}{c}\text { Lipped } \\
\text { channel } 100 \text { x } \\
54 \text { x } 15 \text { x } 1.2 \\
\text { without hole }\end{array}$ & $\begin{array}{c}\text { Ambient } \\
250 \\
400 \\
550 \\
700\end{array}$ & $\begin{array}{c}\text { Lip12a1 } \\
\text { Lip12a2 } \\
\text { Lip12d5 } \\
\text { Lip12b1 } \\
\text { Lip12b225** } \\
\text { Lip12b325 } \\
\text { Lip12d225 } \\
\text { Lip12C140 } \\
\text { Lip12C240 } \\
\text { Lip12C355 } \\
\text { Lip12C455 } \\
\text { Lip12D370* } \\
\text { Lip12D670* } \\
\text { Lip12e170 } \\
\end{array}$ & $\begin{array}{c}55.99 \\
53.46 \\
53.86 \\
50.97 \\
40.04 \\
53.16 \\
47.86 \\
45.75 \\
47.01 \\
23 \\
27 \\
5.52 \\
5.7 \\
8.85 \\
\end{array}$ & $\begin{array}{c}\text { Local and flexible buckling } \\
\text { Local and torsion buckling } \\
\text { Local, distortional buckling and bending } \\
\text { As above } \\
\text { Local buckling \& local crush } \\
\text { Local, distortional buckling and bending } \\
\text { As above } \\
\text { Local buckling \& bending } \\
\text { As above } \\
\text { Distortional buckling } \\
\text { Local buckling \& bending } \\
\text { Local, distortional buckling and bending } \\
\text { As above } \\
\text { As above }\end{array}$ \\
\hline $\begin{array}{c}\text { Lipped } \\
\text { channel } 100 \text { x } \\
56 \times 15 \times 2 \\
\text { without hole }\end{array}$ & $\begin{array}{l}250 \\
400 \\
550 \\
700\end{array}$ & $\begin{array}{l}\text { Lip2a1*** } \\
\text { Lip2a2 } \\
\text { Lip2a5 } \\
\text { Lip2b1 } \\
\text { Lip2d1 } \\
\text { Lip2b225 } \\
\text { Lip2b325 } \\
\text { Lip2C140 } \\
\text { Lip2C240 } \\
\text { Lip2C355 } \\
\text { Lip2a555 } \\
\text { Lip2e155 } \\
\text { Lip2D270* } \\
\text { Lip2D370* } \\
\text { Lip2D470 }\end{array}$ & $\begin{array}{l}110.21 \\
129.16 \\
124.66 \\
116.79 \\
108.97 \\
123.69 \\
123.23 \\
101.87 \\
101.56 \\
45.52 \\
43.33 \\
45.03 \\
12 \\
13.83 \\
15.77 \\
\end{array}$ & $\begin{array}{c}\text { Local buckling } \\
\text { Distortional buckling } \\
\text { As above } \\
\text { Local, distortional buckling } \\
\text { and bending } \\
\text { As above } \\
\text { As above } \\
\text { As above } \\
\text { As above } \\
\text { As above } \\
\text { As above } \\
\text { As above } \\
\text { As above } \\
\text { As above } \\
\text { As above } \\
\text { As above }\end{array}$ \\
\hline $\begin{array}{c}\text { Unlipped } \\
\text { channel } 104 \text { x } \\
63 \text { x } 1.5\end{array}$ & $\begin{array}{c}\text { Ambient } \\
250 \\
400 \\
550 \\
700\end{array}$ & $\begin{array}{l}\text { Unlip15a1 } \\
\text { Unlip15a2 } \\
\text { Unlipc1 } \\
\text { Unlipc225 } \\
\text { Unlipc325 } \\
\text { Unlipc440 } \\
\text { Unlipc540 } \\
\text { Unlipd155 } \\
\text { Unlipd255 } \\
\text { Unlipc670 } \\
\text { Unlipb570 }\end{array}$ & $\begin{array}{c}55 \\
58.02 \\
54.5 \\
49.58 \\
50.77 \\
45.7 \\
44.67 \\
27.07 \\
28.38 \\
9.28 \\
9.21\end{array}$ & $\begin{array}{c}\text { Local buckling } \\
\text { Local buckling } \\
\text { Local buckling and local crush } \\
\text { As above } \\
\text { As above } \\
\text { As above } \\
\text { As above } \\
\text { As above } \\
\text { As above } \\
\text { As above } \\
\text { As above }\end{array}$ \\
\hline & $\begin{array}{l}\text { ** Faulty } \\
* * * \text { Fault }\end{array}$ & $\begin{array}{l}\text { ible due to hig } \\
\text { lue to moveme }\end{array}$ & $\begin{array}{l}\text { e effect on loc } \\
\text { tion frame }\end{array}$ & \\
\hline
\end{tabular}




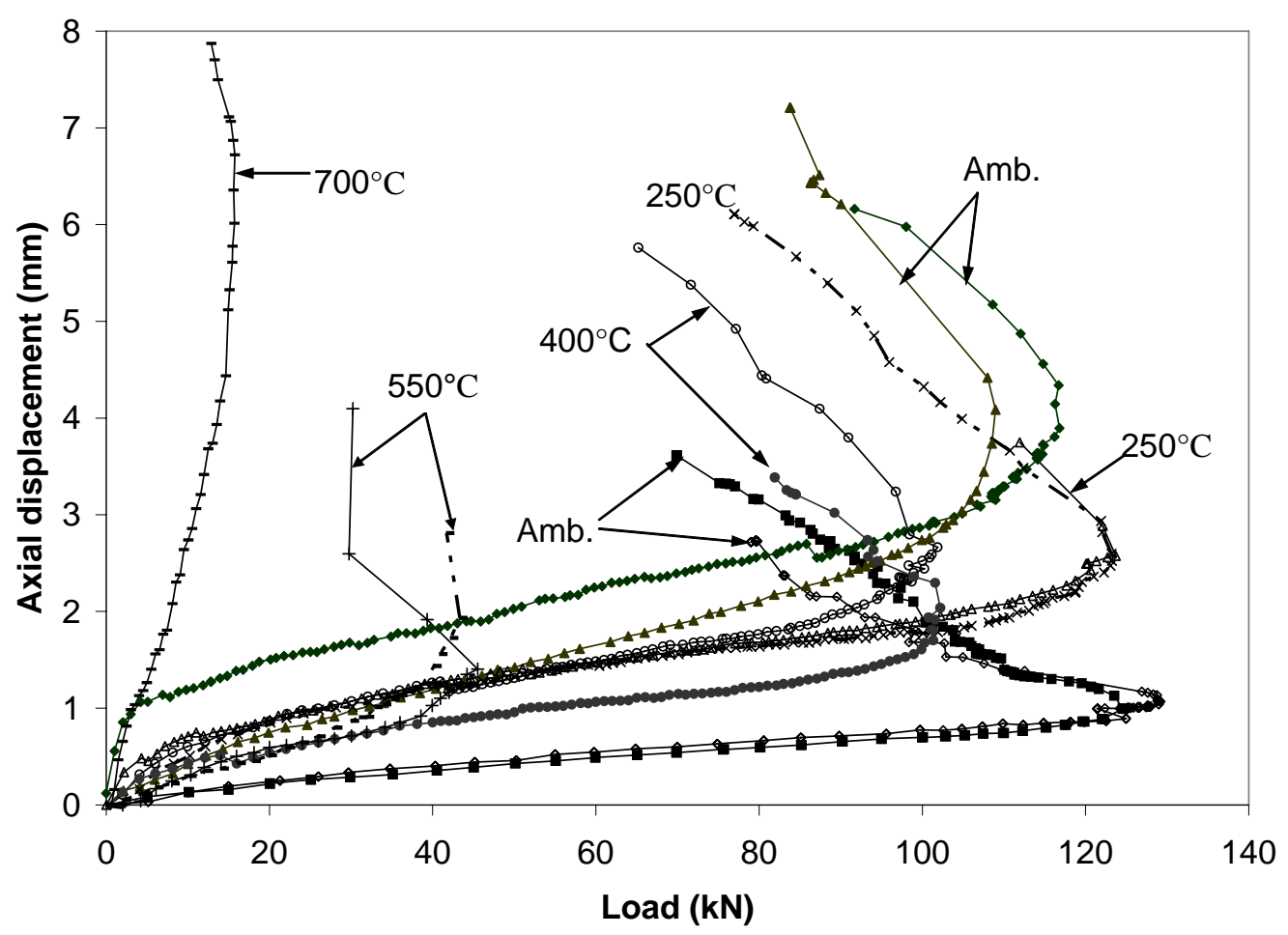

Figure 14. Load-axial deformation relationships of lipped channel 100 x 56 x 15 x 2 without a service hole under different temperatures

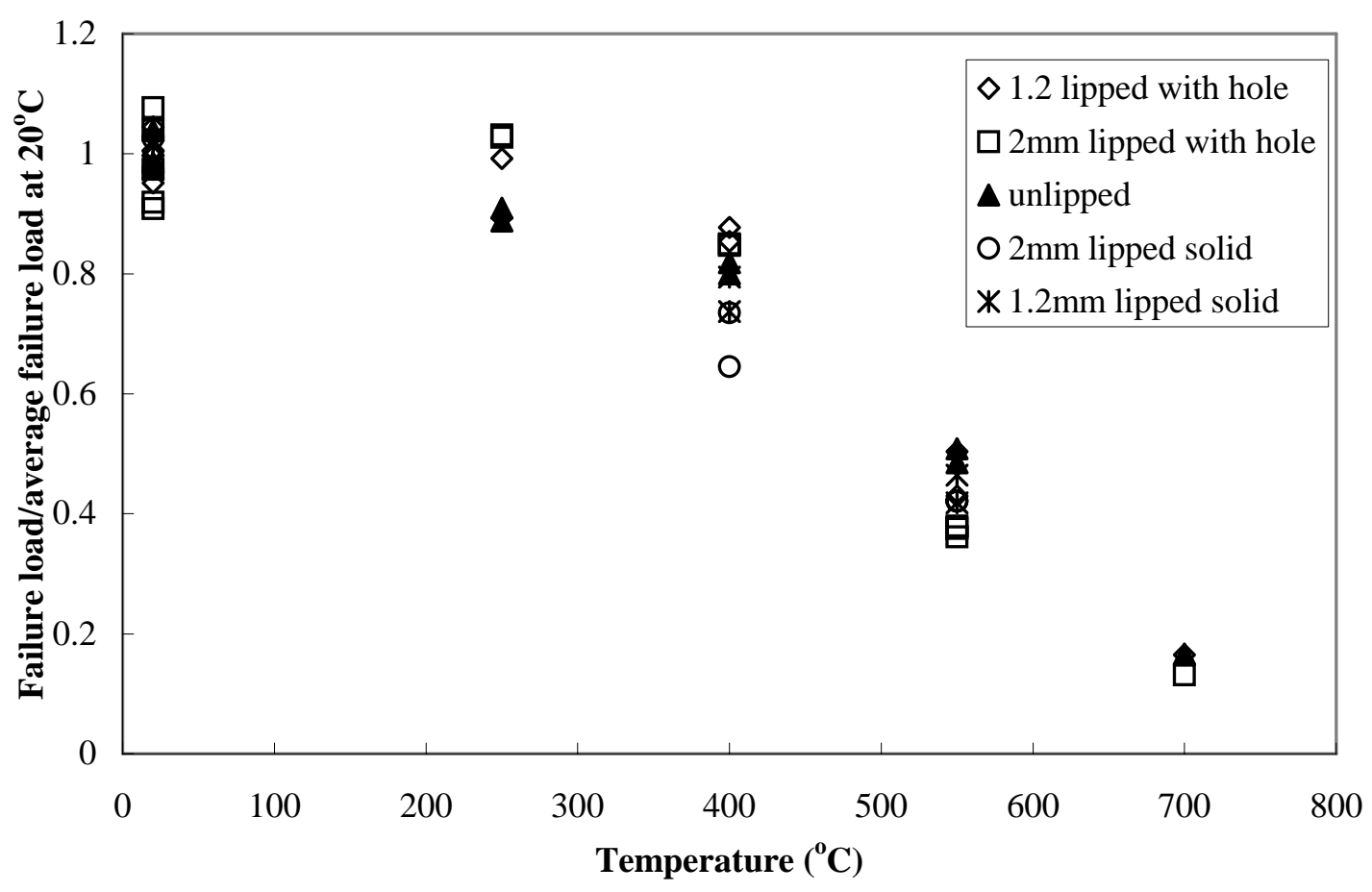

Figure 15. Reduction of column strength as a function of temperature

The uniform high temperature test results were compared against calculations using a number of design calculation methods, including Eurocode 3 Part 1.2 [17] for fire resistance and Eurocode 3 Part 1.3 [20], BS 5950 Part 5 [21] and AISI [22] for ambient temperature. To make use of the ambient temperature methods, the material properties of steel at ambient temperature were replaced by those at high temperatures. Figure 16 summarises the comparison between the test results and 
the different design calculations in which the steady state elevated temperature material properties of Outinen [23] were used. Figure 16 suggests that the BS 5950 Part 5 and AISI methods tend to give higher results than the Eurocode methods. Between the two Eurocode methods, the ambient temperature one (Eurocode 3 Part 1.3) tends to give slightly higher results than the elevated temperature one (Eurocode 3 Part 1.2). Nevertheless, the difference in the predicted results from the different design calculation methods is relatively small, all giving prediction results within about $10 \%$ from the test results. It should be pointed out that Eurocode 3 Part 1.2 recommends that the effective widths at ambient temperature be kept unchanged at elevated temperatures. This saves a great deal of calculation effort, but as shown in Figure 16, it does not seem to suffer any inaccuracy in the design calculation results.

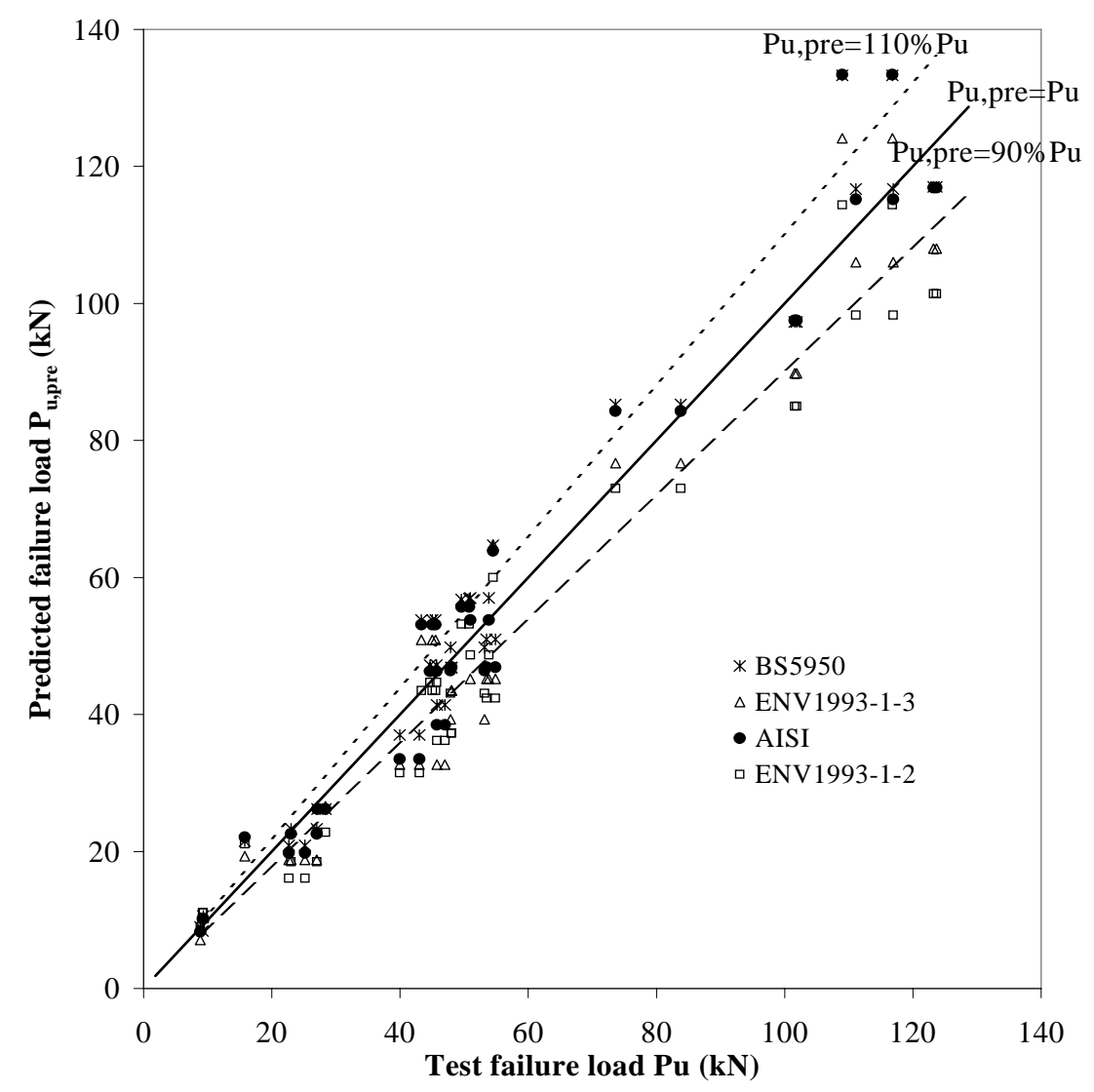

Figure 16. Comparison between test failure loads and predictions of modified BS5950 Part 5, ENV1993-1-3, ENV1993-1-2 and AISI, using Outinen properties

\subsection{Non-uniform temperature study}

It has already been mentioned in a number of places of this paper (e.g. Figure 6) that the temperature distribution in the steel cross-section is non-uniform in both directions. It would be extremely difficult to take this into account in practical design calculations. In the authors' research, ABAQUS simulations were performed to assess whether it would be possible to use simplified temperature distributions in design calculations. The following procedure was adopted:

(1) 2-dimensional ABAQUS simulation was performed to obtain temperature distribution of the steel section under fire exposure to the panel from one side;

(2) ABAQUS simulation was then performed to obtain the ultimate failure load of the steel section using the above temperature distribution; 
(3) The temperature distribution profile in step 1 was represented by two simplified temperature distribution profiles. In simplification 1, the flange temperatures were uniform and their values were the averages of the respective flange temperatures obtained in step 1 . The web temperature distribution was linear. In simplification 2, the flange and web temperature distributions were linear with the flange tip and flange/web junction temperatures taking values from the ABAQUS simulation results in step 1.

(4) ABAQUS simulations were performed to obtain the ultimate failure loads of the steel section using the two simplified temperature profiles of step 3.

The simulations were performed for lipped channel section of dimensions 100 x 54 x 15 x $1.2 \mathrm{~mm}$ for different column heights and different positions of lateral restraints to the column. Figure 17 summaries the simulation results, which indicate that the simulation results using simplification 2 are slightly better correlated than those using simplification 1 with the simulation results using the full non-uniform temperature distribution profile. However, simplification 1 would be much easier to implement in practical design calculations and there was very little loss of accuracy by using this temperature simplification.

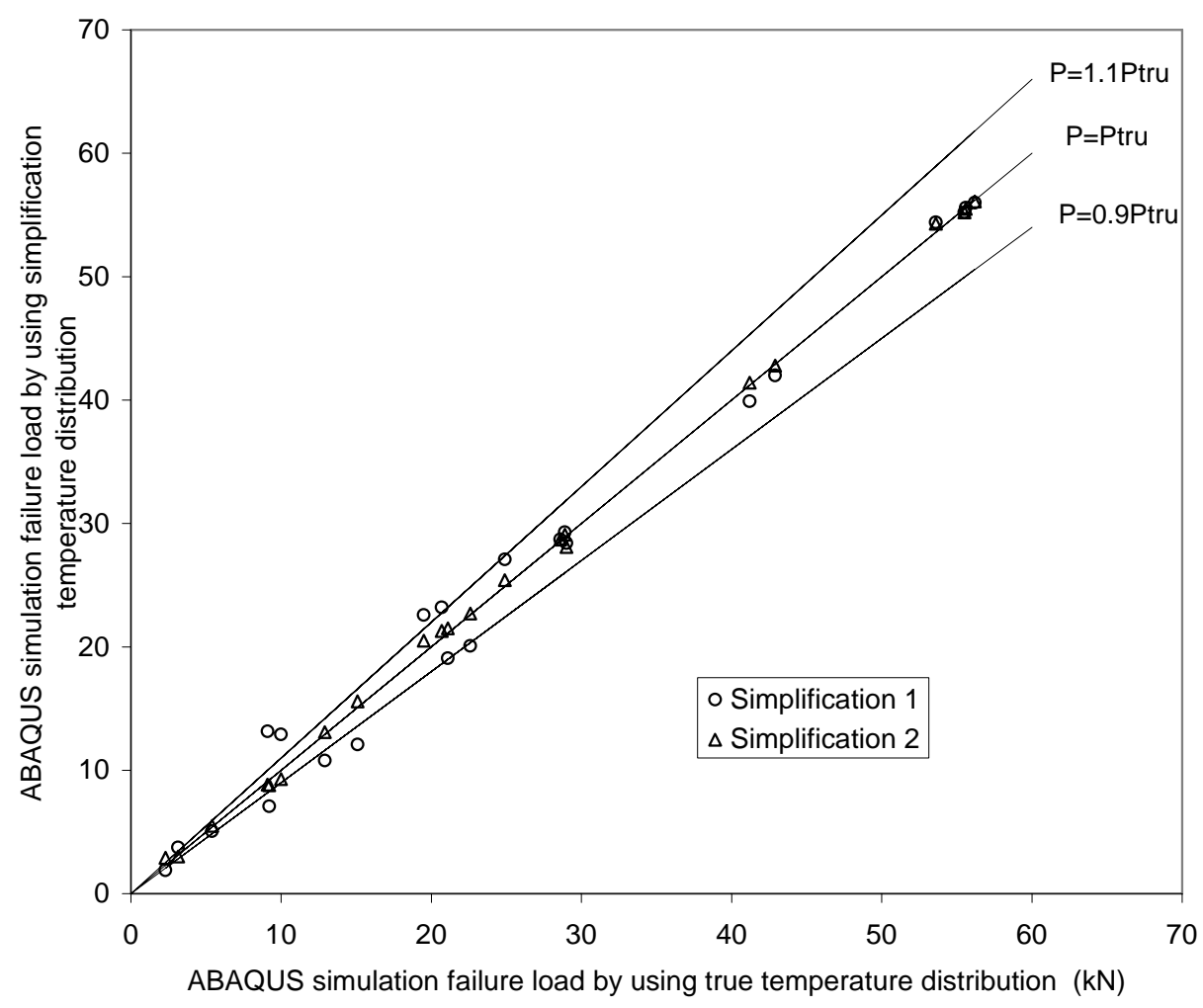

Figure 17. Comparison of ABAQUS predicted failure loads between using the "true" and simplified temperature distributions 


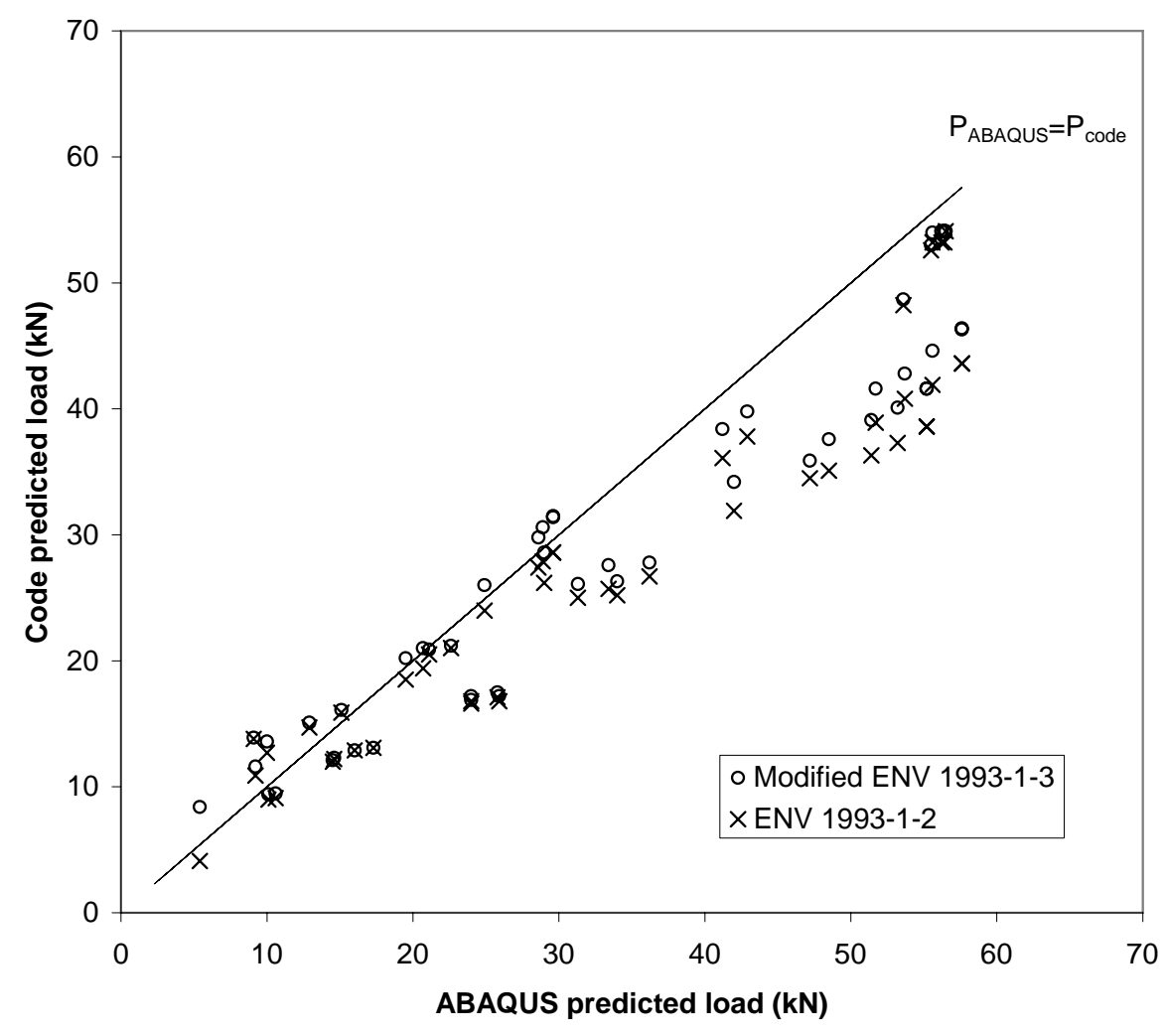

Figure 18. Comparison of failure loads between ABAQUS simulations, modified ENV1993-1-3 and ENV1993-1-2 predictions

Using temperature profile simplification 1, the simulated column strengths were also compared against design calculations using Eurocode 3 Part 1.2 [17] and Eurocode 3 Part 1.3 [20]. Because both design methods are only suitable for applications under uniform temperature distribution, it was necessary to make a number of modifications to account for the effects of non-uniform temperature distributions in the steel section. The principal effects of non-uniform temperature distribution are to induce thermal bowing deflections and to cause a shift in the neutral axis of the steel cross-section. Therefore, the modified calculation method had to deal with bending moments at the steel column supports (due to shift of neutral axis) as well as bending moments in the span (due to combined neutral axis shift and thermal bowing). Also, depending on the stress distributions at the supports and at mid-height as well as the reduced steel strengths at different elevated temperatures, it was necessary to check for stress conditions at different locations. Table 4 summaries the different possible design failure criteria that should be checked, depending on whether the design is according to first yield or partial plasticity. The authors recently published [14] an example of using Eurocode 3 Part 1.2 to calculate the failure strength of a thin-walled column with non-uniform temperature distribution. Even though the effective widths were the same as at ambient temperature, the design calculations still involved pages after pages of calculations, clearly suggesting that the current design calculation method is not suitable as a practical design tool. Nevertheless, Figure 18 shows that the modified design methods based on either Eurocode 3 Part 1.2 or Eurocode 3 Part 1.3 appear to give reasonably acceptable predictions of the numerically calculated column strengths. Figure 18 also confirms the trend shown in Figure 16 that using the elevated temperature method (Eurocode 3 Part 1.2) gives slightly lower column strength than using the ambient temperature method (Eurocode 3 Part 1.3). Since Eurocode 3 Part 1.2 recommends keeping the ambient temperature effective widths unchanged, thus saving some calculation efforts, it is a more suitable design method. 
Table 4. Design yield strength

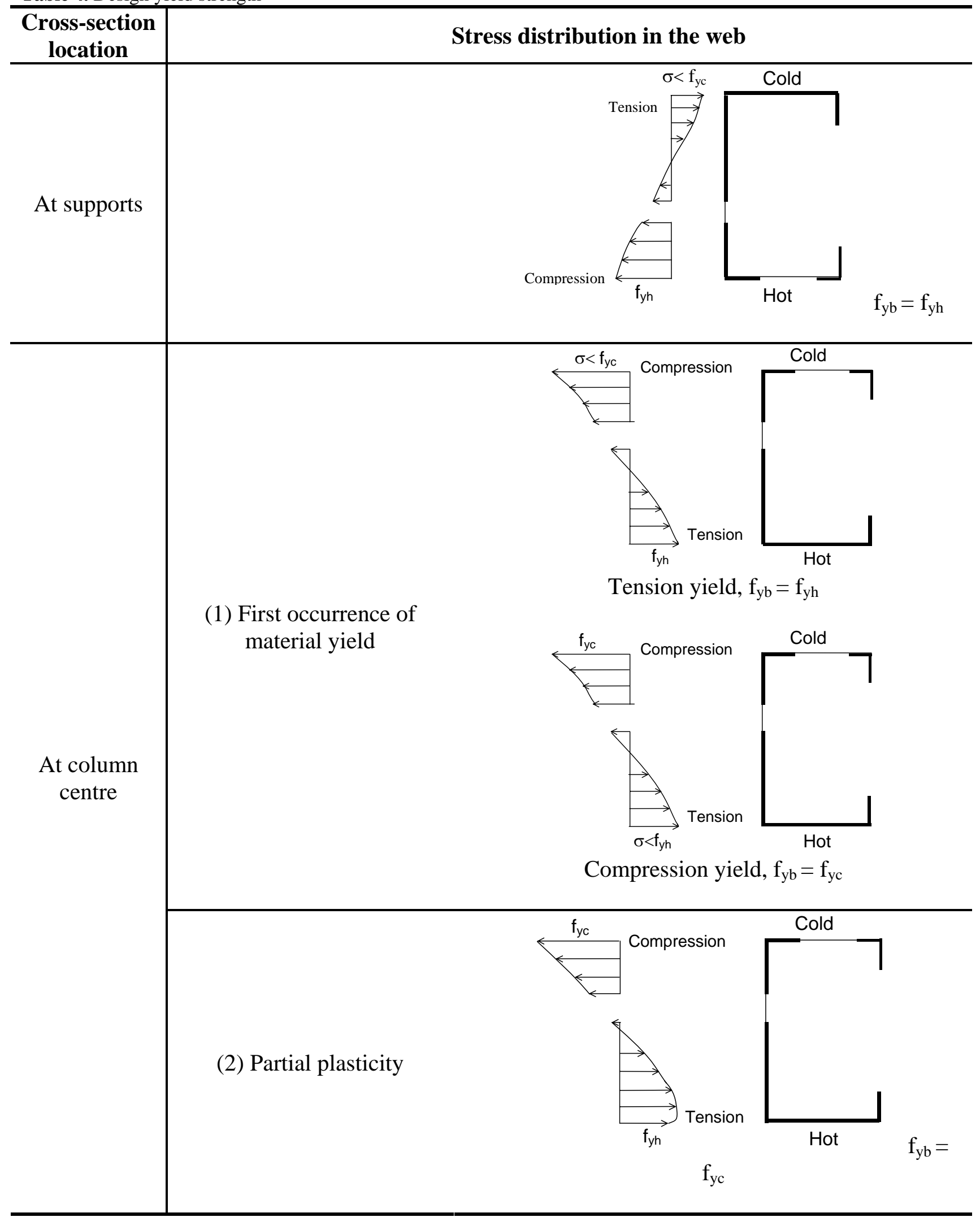

As previously mentioned, the authors conducted 6 fire tests on axially loaded large panels using cold-formed thin-walled steel sections. These panels have also been analysed using the two modified Eurocode design methods. Figure 19 provides a comparison of the recorded and calculated fire resistance times with different assumptions. In this figure, pure thermal bowing refers to the calculation of the panel thermal bowing deflection based purely on temperature 
gradient in the steel section. Magnified thermal bowing refers to using the increased thermal bowing deflection to take into account the reduction in elastic modulus of steel at elevated temperatures. Figure 19 indicates that it is not necessary to calculate the magnified thermal bowing. Design calculations were also performed to assess whether it would be necessary to accurately calculate the shifts in neutral axis in both directions, which would be time consuming. Figure 20 presents a comparison of the calculated results where different assumptions of calculating the neutral axis shifts were made. In Figure 20, $e_{x}$ and $e_{y}$ refer to the shift of neutral axis in the directions parallel to the flanges and the web respectively. Full $e_{x}$ and $e_{y}$ mean that they were both calculated by considering the different steel stiffness at different elevated temperatures. Figure 20 shows that because the steel column was mainly bending about the major axis, it would not be necessary to include the effect of neutral axis shift in the direction parallel to the flanges $\left(e_{x}=0\right)$. To calculate $\mathrm{e}_{\mathrm{y}}$, considering only the two flanges would make the calculations less complicated, but this is at the expenses of much reduced accuracy in the predicted column fire resistance times. It is necessary to include the effect of the web when calculating $\mathrm{e}_{\mathrm{y}}$.

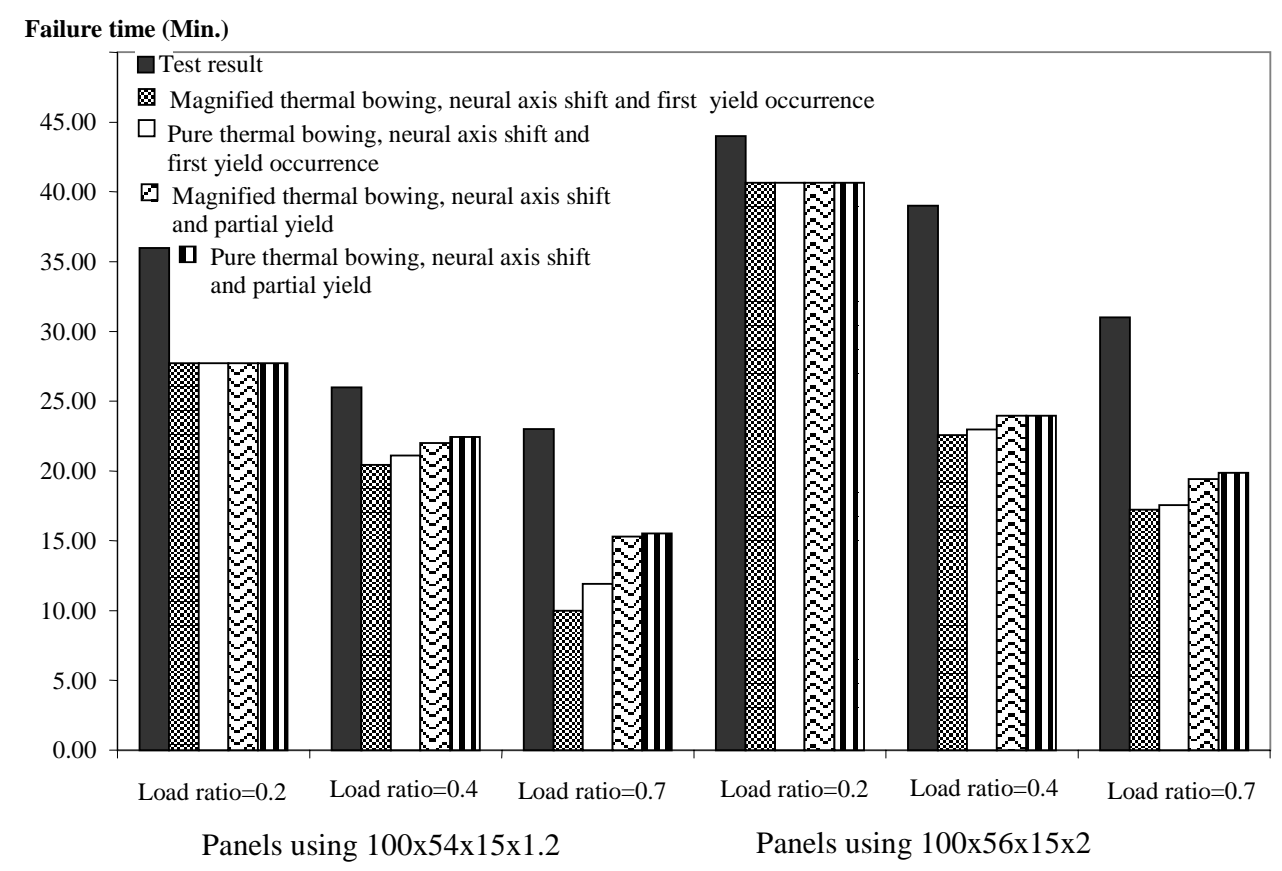

Comparison between test results and ENV 1993-1-2 predictions

Figure 19. Comparison of failure times between test results and predicted results

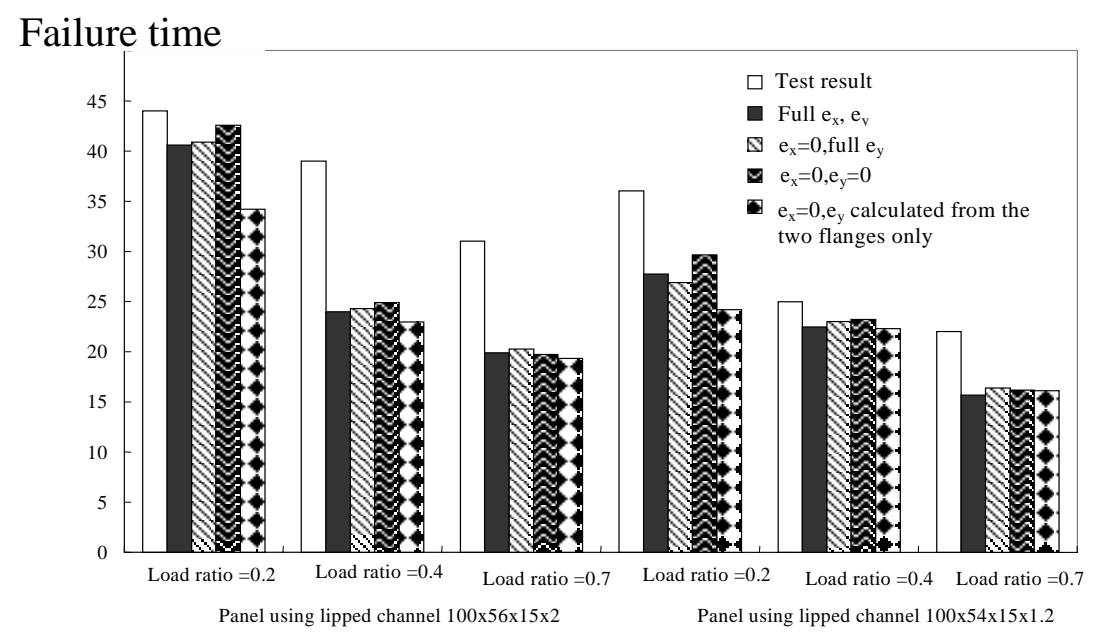

Figure 20. Comparisons of panel failure times between different methods of calculating the shifts of neutral axes 
As part of the $\mathrm{PhD}$ project of the third author, a fire test was recently conducted on a panel consisting of three lipped steel channel sections of dimensions 100 x 54 x 15 x 1.2 mm with perforated web, with one layer of gypsum plasterboard on each side and interior insulation of type Isowool 1000. As shown in Table 3, this test is directly comparable to test "panel-5" which had no perforation. Analysis is still being carried out to gain fundamental understanding of structural behaviour of this type of construction in fire. In the meantime, ABAQUS simulations have been performed to investigate the effect of gypsum plasterboard on the structural performance of the steel section, by removing the lateral and torsional restraints provided by the gypsum plasterboard on the exposed side at the locations of joint between the gypsum plasterboard and the steel section. In these simulations, the steel temperatures were the same as those measured during the fire test.

Table 3. Large scale, loaded panel fire test specimens

\begin{tabular}{ccccc}
\hline ID. & Steel sections & $\begin{array}{c}\text { Load } \\
\text { ratio }\end{array}$ & $\begin{array}{c}\text { Load in } \\
\text { individual } \\
\text { channel (kN) }\end{array}$ & $\begin{array}{c}\text { Failure time } \\
\text { (min) }\end{array}$ \\
\hline panel-1 & $100 \times 56 \times 15 \times 2$ & 0.2 & 20.6 & 44 \\
panel-2 & As above & 0.4 & 41 & 39 \\
panel-3 & As above & 0.7 & 72 & 31 \\
panel-4 & $100 \times 54 \times 15 \times 1.2$ & 0.2 & 12 & 36 \\
panel-5 & As above & 0.4 & 23 & 25 \\
panel-6 & As above & 0.7 & 41 & 22 \\
panel-P & As above (perforated) & $\approx 0.4$ & 23 & 21.5 \\
\hline
\end{tabular}

Figure 21 compares the test results against different ABAQUS simulations in which the restraints provided by the gypsum plasterboard on the fire exposed side were removed at different times. It indicates that, as expected, the earlier the removal of these restraints, the lower the panel fire resistance. However, since the same measured steel temperatures were used in all simulations, the simulated panel failure time was not particularly sensitive to the timing of removal of these restraints. It appeared that the simulation result was the closest to the test result when the restraints were removed at around 20 minutes. Shortly afterward (21 minutes), the panel failed, correlating well with the recorded panel failure time of 21.5 minutes. The recorded temperatures of this test are shown in Figure 22. At 20 minutes, the average temperature of the fire exposed gypsum plasterboard was about $600^{\circ} \mathrm{C}$, suggesting that the gypsum plasterboard would have lost its restraining effect at this temperature. If the restraints provided by the gypsum plasterboard on the fire exposed side were kept throughout the numerical simulation, the panel failure time was 23.7 minutes. It should be pointed out that at this time, the furnace had already been switched off during the actual test, however, the steel temperatures were still increasing, whereby allowing the numerical simulation to predict panel failure after the peak fire temperature. Figure 22 also reveals that the steel temperatures on the exposed side (thermocouples 2 and 3) jumped after failure of the test specimen, indicating that the exposed gypsum plasterboard had fallen. Since thermocouples 2 and 3 had recorded much lower steel temperatures than the exposed gypsum plasterboard surface temperature (recorded by thermocouple 1) before panel failure, it may be deduced that the exposed gypsum plasterboard had remained in place before panel failure, which confirms the observation deduced from Figure 8. 


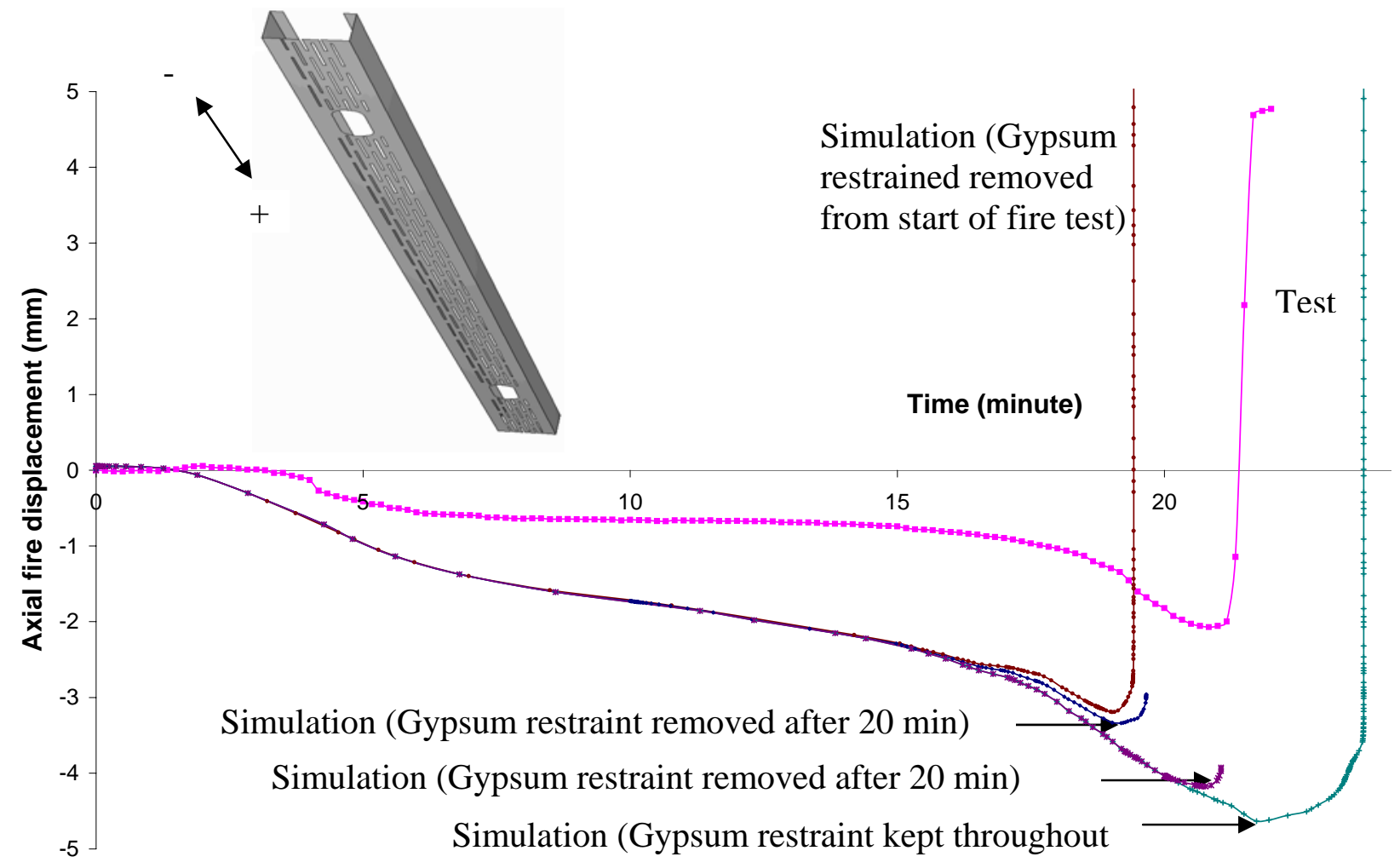

Figure 21. Comparison between test and simulation results for perforated section, gypsum plasterboard restraining effect removed at different times of simulation

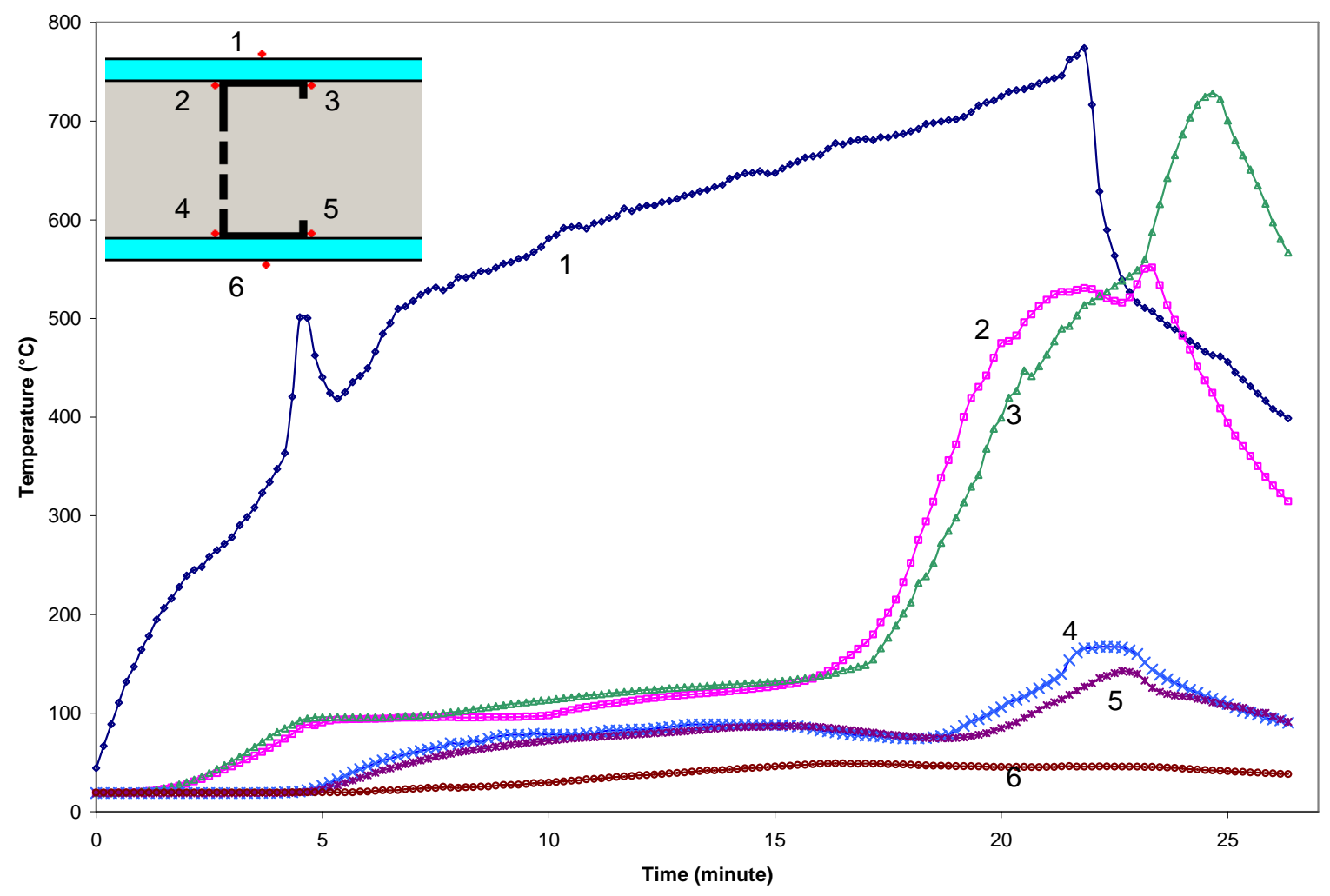

Figure 22. Temperatures in loaded, perforated steel section 


\section{CONCLUSIONS}

This paper has presented a summary of an extensive experimental, numerical and design calculation study of cold-formed thin-walled steel sections under compression in fire. The following main conclusions may be drawn:

(1) The structural behaviour of thin-walled steel sections under compression in fire is closely related to its thermal behaviour. The thermal behaviour of the steel section forming part of a panel system incorporating gypsum plasterboards and interior insulation is strongly affected by the behaviour of these two parts. Accurate simulation of temperatures attained in the steel section depends critically on accurate information of the thermal properties of these materials as well as whether the gypsum plasterboard would fall.

(2) Present knowledge is not sufficient to enable prediction of gypsum plasterboard falling under fire conditions. This does not only depend on temperatures attained in the gypsum plasterboard, but also on whether the gypsum plasterboard is loaded or not as well as its size.

(3) For design purpose, it is possible to considerably simplify the temperature distributions in thin-walled steel sections with non-uniform temperature distribution. For the steel channel section in the panel system discussed in this paper, it may be assumed that each flange of the channel section has uniform temperature and the web temperature distribution is linear. Also the existing design methods for cold-formed thin-walled steel structures may be modified to take into consideration non-uniform temperature distributions and reductions in strength and stiffness of steel at elevated temperatures.

(4) Even if gypsum plasterboard could remain intact during the entire fire exposure, it could lose its restraining effects at high temperatures. Numerical simulations and design calculations should take this into account. For the Fireline gypsum plasterboard manufactured by British Gypsum, it is reasonable to discard the gypsum plasterboard restraining effect when the average temperature in the gypsum plasterboard has reached $600^{\circ} \mathrm{C}$.

(5) By suitable modification of the ENV 1993-1-2 procedures to include the effects of non-uniform temperature distribution in the steel section, it is possible to obtain reasonable and conservative predictions of the ultimate loads and failure times of the samples tested in this study.

\section{ACKNOWLEDGEMENTS}

This paper is based on a research project supported by the UK's Engineering and Physical Science Research Council (EPSRC) under grant GR/M56319 and the PhD research project of the third author, sponsored by the Syrian Damascus University. 


\section{REFERENCES}

[1] Sultan, M.A., A model for predicting heat transfer through noninsulated unloaded steel-stud gypsum board wall assemblies exposed to fire, Fire Technology, third quarter, 1996, pp. 239-259.

[2] Alfawakhiri, F., Sultan, M.A. and MacKinnon, D.H., Fire resistance of loadbearing steel-stud walls protected with gypsum board: A review, Fire Technology, 35(4), 1999, pp. 308-335.

[3] Kodur, V.R. and Sultan, M.A., Factors governing fire resistance of loadbearing steel stud walls, NRCC-45211, National Research Council Canada, 2001.

[4] Sultan, M.A. and Lougheed, G.D., Results of fire resistance tests on full-scale gypsum board wall assemblies, Internal report No. 833, Institute of Research in Construction, National Research Council Canada, 2002.

[5] Benichou, N. and Sultan M.A., Design considerations for fire resistance of lightweight-framed assemblies, NRCC-38776, National Research Council Canada, 2003.

[6] Sakumoto, Y., Hirakawa, T., Masuda, H. and Nakamura, K., Fire resistance of walls and floors using light-gauge steel shapes, ASCE Journal of Structural Engineering, 129(11), 2003, pp. 1522-1530.

[7] CEN, Draft prENV 1991-1-2, Eurocode 1, Basis of design and actions on structures, Part 1.2: Actions on Structures - Actions on structures exposed to fire, British Standards Institution, 2000.

[8] Feng, M., Wang, Y.C. and Davies, J.M., Structural behaviour of cold-formed thin-walled short steel channel columns at elevated temperatures. Part 1: experiments. Thin-Walled Structures, 41, 2003, pp. 543-570.

[9] Feng, M., Wang, Y.C. and Davies, J.M., Structural behaviour of cold-formed thin-walled short steel channel columns at elevated temperatures. Part 2: design calculations and numerical analysis. Thin-Walled Structures, 41, 2003, pp. 571-594.

[10] Feng, M., Wang, Y.C. and Davies, J.M., Thermal performance of cold-formed thin-walled steel panel systems in fire, Fire Safety Journal, 38, 2003, pp. 365-394.

[11] Feng, M., Wang, Y.C. and Davies, J.M., An assessment of the ultimate strength of cold-formed thin-walled steel channel columns exposed to fire on one side, Fire Safety Journal, 38, 2003, pp. 679-707.

[12] Feng, M., Wang, Y.C. and Davies, J.M., A numerical imperfection sensitivity study of cold-formed thin-walled steel tubular columns at uniform elevated temperatures, Thin-Walled Structures, 44(4), 2004, pp. 533-555.

[13] Feng, M. and Wang, Y.C., An experimental study of full-scale cold-formed thin-walled steel structural panels under fire conditions, Fire Safety Journal, 40(1), 2005, pp. 43-63. 
[14] Feng, M. and Wang, Y.C., An analysis of the structural behaviour of axially loaded full-scale cold-formed thin-walled steel structural panels tested under fire conditions, Thin-Walled Structures, 43, 2005, pp. 291-332.

[15] BSI, British Standard 476, Fire Tests on Building Materials and Structures, Part 20: Method for Determination of the Fire Resistance of Elements of Construction (General Principles), British Standards Institution, 1987.

[16] ABAQUS Standard User’s Manual, Hibbit, Karlsson \& Sorensen Inc., 1998.

[17] CEN, ENV 1993-1-2, Eurocode 3; Design of steel structures, Part1.2: General rules, structural fire design, British Standards Institution, 2001.

[18] Wang H.B., Heat transfer analysis of components of construction exposed to fire, PhD thesis, University of Salford, 1995.

[19] Lawson R M., Building design using cold formed steel sections: Fire protection. The Steel Construction Institute, Publication P129, 1993.

[20] CEN, EN1993-1-3, Eurocode 3: Design of steel structures, Part 1.3: General rules, supplementary rules for cold formed thin gauge members and sheeting, British Standards Institution, 1996.

[21] BSI, British Standard: Structural use of steelwork in building, Part 5: Code of practice for design of cold formed thin gauge sections, British Standard Institution, 1998.

[22] AISI, Specification for the design of cold-formed steel structural members with commentary 1996 edition supplement No.1, Washington DC: American Iron and Steel Institute, 1999.

[23] Outinen, J., A study for the development of the design of steel structures in fire condition. Proceedings of the first international workshop on structures in fire, page 269-281, Copenhagen, 2000. 